\title{
Products and kinetics of the reactions of an alkane monolayer and a terminal alkene monolayer with $\mathrm{NO}_{3}$ radicals
}

\author{
Simone Gross ${ }^{1}$ and Allan K. Bertram ${ }^{1}$ \\ Received 14 August 2008; revised 4 November 2008; accepted 14 November 2008; published 27 January 2009.
}

[1] The reactions of an alkanethiol and a terminal alkenethiol self-assembled monolayer with $\mathrm{NO}_{3}$ radicals (in the presence of $\mathrm{NO}_{2}$ and $\mathrm{O}_{2}$ ) were studied. For the alkane monolayer, infrared (IR) spectroscopy and time-of-flight secondary ion mass spectrometry (ToF-SIMS) confirmed the formation of organonitrates $\left(\mathrm{RONO}_{2}\right)$. The observation of organonitrates is in contrast to the recent X-ray photoelectron spectroscopy (XPS) data, which showed very little nitrogen-containing surface species. The identification of organonitrates may help explain why significant volatilization of the organic chain was not observed in recent studies of alkane monolayer oxidation by $\mathrm{NO}_{3}$ radicals. The reactive uptake coefficient $(\gamma)$ of $\mathrm{NO}_{3}$ on alkene monolayers determined in our study is higher than the values obtained in a recent study using liquid and solid alkene bulk films. A possible reason for this difference may be the location of the double bond at the interface. Using the $\gamma$ value determined in our studies, we show that under conditions where $\mathrm{NO}_{3}$ is high the lifetime of an alkene monolayer in the atmosphere may be short (approximately $20 \mathrm{~min}$ ). XPS, IR, and ToF-SIMS were used to identify surface functional groups after the oxidation of the alkene monolayers by $\mathrm{NO}_{3}$. The results are consistent with the formation of $\mathrm{C}-\mathrm{O}$, aldehyde/ketone, carboxylic groups, and nitrogen containing species.

Citation: Gross, S., and A. K. Bertram (2009), Products and kinetics of the reactions of an alkane monolayer and a terminal alkene monolayer with $\mathrm{NO}_{3}$ radicals, J. Geophys. Res., 114, D02307, doi:10.1029/2008JD010987.

\section{Introduction}

[2] Field measurements have shown that organic material is abundant in the atmosphere, comprising $10-90 \%$ of the total fine particulate mass [Kanakidou et al., 2005]. This organic material can be in the form of pure organic aerosol particles, or alternatively the organic substances can be mixed with inorganic material. In the latter case, the organic material can form coatings on the surface of aqueous particles [Ellison et al., 1999; Gill et al., 1983] or coatings adsorbed on the surface of solid particles, such as mineral dust [Usher et al., 2003a].

[3] Recently the oxidation of condensed phase organic material by atmospheric radicals has attracted significant attention [Arens et al., 2002; Bertram et al., 2001; Bröske et al., 2003; D'Andrea et al., 2008; Docherty and Ziemann, 2006; Eliason et al., 2004; Ellison et al., 1999; Esteve et al., 2003, 2004, 2006; George et al., 2007; Gross and Bertram, 2008; Hearn et al., 2007; Hearn and Smith, 2006; Hung et al., 2005; Inazu et al., 1997; Ishii et al., 2000; Kahan et al., 2006; Knopf et al., 2006; Lai and FinlaysonPitts, 1991; Lambe et al., 2007; Mak et al., 2007; McNeill et al., 2007, 2008; Moise and Rudich, 2001; Moise et al., 2002; Molina et al., 2004; Perraudin et al., 2005; Robinson et al., 1995; Rudich, 2003; Rudich et al., 2007; Vlasenko et al.,

\footnotetext{
${ }^{1}$ Department of Chemistry, University of British Columbia, Vancouver, British Columbia, Canada.

Copyright 2009 by the American Geophysical Union. 0148-0227/09/2008JD010987\$09.00
}

2008; Wang et al., 2000]. Field measurements suggest that this chemistry may change the composition of atmospheric particles [Robinson et al., 2006]. Some studies suggest that these heterogeneous reactions can lead to rapid volatilization of organic particulate matter [McNeill et al., 2008; Molina et al., 2004; Vlasenko et al., 2008]. The reactions may also be a significant sink for organic particles [Molina et al., 2004] and a major source of volatile organic carbon (VOC) in the atmosphere [Ellison et al., 1999; Kwan et al., 2006]. Other studies suggest that under certain conditions these radical heterogeneous reactions may not be a significant source of VOC material [see, e.g., Docherty and Ziemann, 2006; George et al., 2007; Hearn et al., 2007; Knopf et al., 2006; Moise and Rudich, 2001].

[4] Recently it has been suggested that radical-organic heterogeneous chemistry may vary significantly depending on the phase of the organic, the organic structure, oxygen concentration, and NO concentration [Ziemann, 2007]. These factors are expected to influence the relative importance of the different reaction pathways, and the importance of volatilization. More work with a range of experimental conditions is required to better understand the effect of these various factors on heterogeneous radical-organic chemistry so that laboratory results can accurately be extrapolated to the atmosphere.

[5] To improve the understanding of radical-organic heterogeneous chemistry, we have studied the reaction between $\mathrm{NO}_{3}$ radicals (in the presence of $\mathrm{O}_{2}$ and $\mathrm{NO}_{2}$ ) and two types of organic self-assembled monolayers (SAMs). Studies with these surfaces enabled us to probe radical-organic reactions 


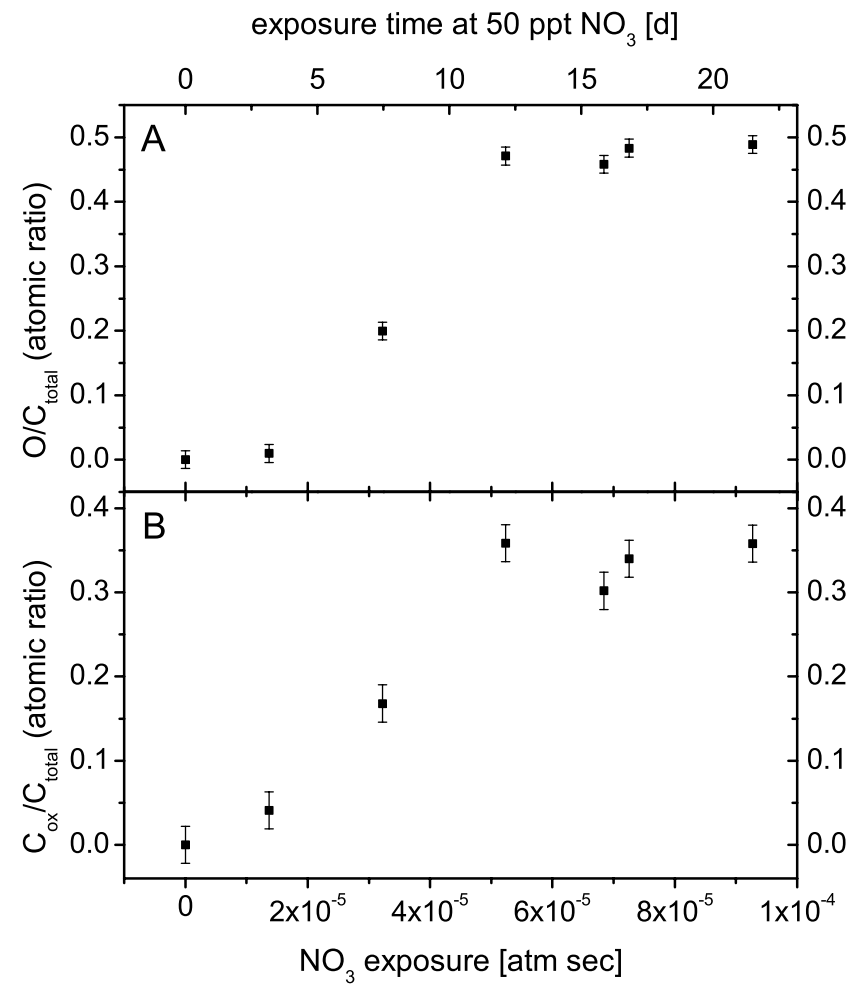

Figure 1. XPS results of $\mathrm{NO}_{3}$ exposed ODT from Knopf et al. [2006]. (a) Atomic ratio of total oxygen, O, to total carbon, $\mathrm{C}_{\text {total }}$, as a function of $\mathrm{NO}_{3}$ exposure. (b) Atomic ratio of oxidized carbon, $\mathrm{C}_{\mathrm{ox}}$, to total carbon, $\mathrm{C}_{\text {total }}$, as a function of $\mathrm{NO}_{3}$ exposure. The bottom axis gives $\mathrm{NO}_{3}$ exposure $(\mathrm{atm} \mathrm{sec})$ and the top axis gives total exposure time at $50 \mathrm{ppt}$ $\mathrm{NO}_{3}$ (days). Both $x$ axes are valid for Figures $1 \mathrm{a}$ and $1 \mathrm{~b}$.

confined to the gas-surface interface, and separate surface and bulk processes [Rudich, 2003]. The results from these studies may provide insight into the reactivity of organics adsorbed on solid substrates such as mineral dust particles or urban surfaces [Diamond et al., 2000; Donaldson et al., 2005; Simpson et al., 2006; Usher et al., 2003a], and the reactivity of organic coatings on aqueous particles in the atmosphere [Ellison et al., 1999]. These results may also provide insight into the reactivity of solid surfaces [Vieceli et al., 2004]. The self-assembled monolayers we studied were an alkane monolayer (1-octadecanethiol $\mathrm{C}_{18} \mathrm{H}_{38} \mathrm{~S}$ ), referred to as ODT; and a terminal alkene monolayer (undec-10-ene-1-thiol, $\mathrm{C}_{11} \mathrm{H}_{22} \mathrm{~S}$ ), referred to as UDT. Differences in behavior between ODT and UDT can be attributed to the presence of the terminal double bond in UDT and not to the difference in chain length, since properties of hydrocarbon thiols on gold are thought to be independent of chain length for chains of more than $10 \mathrm{C}$ atoms [Bain et al., 1989].

[6] $\mathrm{NO}_{3}$ radicals were chosen for these studies since $\mathrm{NO}_{3}$ is an abundant radical in the troposphere with concentrations in the polluted nighttime of 60-300 ppt [Aldener et al., 2006; Platt et al., 1980; Stutz et al., 2004] with measured extremes of up to $430 \mathrm{ppt}$ [Finlayson-Pitts and Pitts, 2000]. Also it has recently been shown that reactions between $\mathrm{NO}_{3}$ radicals and organic particles can be efficient and comparable in atmospheric importance to $\mathrm{OH}$-organic heterogeneous reactions under certain conditions [Gross and Bertram, 2008; Karagulian and Rossi, 2007; Knopf et al., 2006; Mak et al., 2007; Moise et al., 2002].

[7] In our experiments, as mentioned above, the $\mathrm{NO}_{3}$ reactions were performed in the presence of $\mathrm{O}_{2}$ and $\mathrm{NO}_{2}$ $\left(\mathrm{NO}_{2}\right.$ is a byproduct of the method of producing $\left.\mathrm{NO}_{3}\right)$. This should complement several previous radical-organic heterogeneous studies which were carried out free of $\mathrm{NO}_{2}$. An understanding of the effect of $\mathrm{NO}_{2}$ concentrations may help explain some of the discrepancies in the literature on radicalorganic heterogeneous reactions and they are expected to be of atmospheric relevance, since many atmospheric conditions have high $\mathrm{NO}_{2}$ concentrations [Finlayson-Pitts and Pitts, 2000].

[8] The following research expands on our previous study of $\mathrm{NO}_{3}$ radicals with ODT monolayers. In our previous study we used X-ray photoelectron spectroscopy (XPS) to investigate the oxidation of ODT monolayers [Knopf et al., 2006]. Shown in Figure 1 are some of the results from this previous work [Knopf et al., 2006]. The XPS data also show that less than $11 \%$ of the carbon chain was removed (i.e., volatilized) owing to $\mathrm{NO}_{3}$ exposure. In addition, the XPS profiles were consistent with the formation of (1) C-O groups, (2) ketones or aldehydes, and (3) carboxylic acid groups. However, nitrogen species were not detected on the surface. As noted previously, nitrogen species (such as organonitrates) may have formed during the oxidation chemistry, but decomposed during the XPS measurements. In the following, we expand on our previous measurements by using infrared (IR) spectroscopy and time-of-flight secondary ion mass spectrometry (ToF-SIMS) to determine if surface nitrogen species do form during the oxidation of ODT monolayers by $\mathrm{NO}_{3}$. This information is needed to determine if radical-organic reactions on monolayers are significantly different from the same reactions in the gas and liquid phase.

[9] In addition to studying reactions of an alkane monolayer, we also studied reactions of a terminal alkene monolayer. In this case, we performed detailed studies, since there have not been any previous studies of $\mathrm{NO}_{3}$ radicals with alkene monolayers. Using a flow tube reactor, we measured the reactive uptake coefficient $\gamma$ of $\mathrm{NO}_{3}$ on the alkene monolayer as a function of $\mathrm{NO}_{3}$ exposure. $\gamma$ is defined as the fraction of collisions of the gas-phase reactant with the surface that leads to reactive uptake. These data were then used to determine how fast alkene surfaces and monolayers will be oxidized by $\mathrm{NO}_{3}$ radicals in the atmosphere. We also carried out detailed surface-product studies. The results from these measurements were used to develop a mechanism for the $\mathrm{NO}_{3}$-alkene monolayer reaction.

[10] Below we present the results for the alkane and alkene monolayers. We discuss reaction mechanisms for both monolayers. One of the main conclusions from these studies is that nitrogen containing species are significant products of the heterogeneous reactions studied.

\section{Experimental Section}

\subsection{Chemicals}

[11] Octadecanethiol $\left(98 \%, \mathrm{C}_{18} \mathrm{H}_{38} \mathrm{~S}, \mathrm{ODT}\right)$ was purchased from Sigma-Aldrich and used without further purification. Undec-10-ene-1-thiol $\left(\mathrm{C}_{11} \mathrm{H}_{22} \mathrm{~S}\right.$, UDT) was synthesized according to the procedure described by Peanasky and 
McCarley [1998]. $\mathrm{NO}_{2}(99.5 \%)$ was purchased from Matheson, $\mathrm{N}_{2}(99.999 \%), \mathrm{O}_{2}(99.993 \%)$ and $\mathrm{He}(99.999 \%)$ were purchased from Praxair. $\mathrm{N}_{2} \mathrm{O}_{5}$ was generated by reacting $\mathrm{NO}_{2}$ with an excess amount of $\mathrm{O}_{3}$ in a flow system as described by Schott and Davidson [1958]. The solid $\mathrm{N}_{2} \mathrm{O}_{5}$ crystals were stored at $197 \mathrm{~K} . \mathrm{NO}_{3}$ radicals were obtained by thermal conversion of gaseous $\mathrm{N}_{2} \mathrm{O}_{5}$ to $\mathrm{NO}_{3}$ and $\mathrm{NO}_{2}$ at $430 \mathrm{~K}$ in a Teflon-coated glass oven [Knopf et al., 2006]. This dissociation of $\mathrm{N}_{2} \mathrm{O}_{5}$ was almost complete with residual $\mathrm{N}_{2} \mathrm{O}_{5}$ concentrations in the flow cell of approximately $1-3 \%$ of $\mathrm{NO}_{3}$ concentrations.

\subsection{Monolayer Preparation}

[12] Monolayers were prepared on either gold coated silicon wafers for condensed phase product studies or a cylindrical gold coated tube for measurements of reactive uptake coefficients. These wafers and the cylindrical gold coated tube (inner diameter $1.91 \mathrm{~cm}$, length $15 \mathrm{~cm}$ ) were first cleaned in piranha solution $\left(\mathrm{H}_{2} \mathrm{SO}_{4}(96 \%) / \mathrm{H}_{2} \mathrm{O}_{2}(30 \%)=3: 1\right)$, then rinsed with Millipore water $(18 \mathrm{M} \Omega)$ and distilled ethanol. The wafers or the tubes were then immersed in a $1-\mathrm{mM}$ solution of 1-octadecanethiol (ODT) or undecenethiol (UDT) in distilled ethanol for $\geq 24 \mathrm{~h}$ [Ishida et al., 1997]. Subsequently, samples were cleaned in ethanol using an ultrasonic bath for $1 \mathrm{~min}$ and rinsed with Millipore water for approximately $3 \mathrm{~min}$ ( $5 \mathrm{~min}$ for gold tube). This cleaning procedure was repeated two more times. SAM coated gold surfaces were then dried under a stream of ultra-high-purity $\mathrm{N}_{2}$.

\subsection{Measurements of the Reactive Uptake Coefficient}

[13] A temperature controlled, cylindrical flow tube reactor coupled to a chemical ionization mass spectrometer (CIMS) was employed for measurements of the reactive uptake coefficient $(\gamma)$ of $\mathrm{NO}_{3}$ on alkene monolayers at $298 \mathrm{~K}$. The inner wall of a gold coated tube was coated with a UDT SAM and inserted into the flow reactor. $\mathrm{NO}_{3}$ radicals were added through a movable injector as previously described [Gross and Bertram, 2008; Knopf et al., 2006; Mak et al., 2007]. $\mathrm{NO}_{3}$ concentrations of $(1-2) \times 10^{11}$ molecule $\mathrm{cm}^{-3}$ were used in the presence of $\mathrm{O}_{2}\left((1.1-1.3) \times 10^{16}\right.$ molecule $\left.\mathrm{cm}^{-3}\right)$. The uncertainty in the $\mathrm{NO}_{3}$ concentration was approximately $\pm 40 \%$. Helium was used as a carrier gas for $\mathrm{NO}_{3}$. Total pressure in the flow reactor was $2.3-2.5$ torr. $\mathrm{NO}_{3}$ was detected at the exit of the flow cell using chemical ionization with $\mathrm{I}^{-}$(obtained by passing trace amounts of $\mathrm{CH}_{3} \mathrm{I}$ in $\mathrm{N}_{2}$ through a ${ }^{210}$ Po source). The $\mathrm{NO}_{3}$ signal was monitored while the injector was pulled back at equal increments, exposing UDT surfaces to $\mathrm{NO}_{3}$ radicals. Calculation procedures for the determination of $\gamma$ from the depletion of the CIMS signal of the gas-phase reactant (here $\mathrm{NO}_{3}$ ) during exposure to an organic surface have been described elsewhere [Knopf et al., 2005].

\subsection{Product Studies as a Function of Exposure}

[14] The flow reactor was also used to expose SAMs on $\mathrm{Au}$ coated Si plates to $\mathrm{NO}_{3}$ for subsequent XPS, IR, $\mathrm{H}_{2} \mathrm{O}$ contact angle, and ToF-SIMS analysis. $\mathrm{NO}_{3}$ exposure levels ranged from 0 to $9.06 \times 10^{-5} \mathrm{~atm}$ sec (an exposure of $0-21$ days at $50 \mathrm{ppt} \mathrm{NO}_{3}$ ). Experiments were performed at $298 \mathrm{~K}$, at a pressure of 2.3-2.7 torr, using $\mathrm{NO}_{3}$ concentrations of $(1-5) \times$ $10^{11}$ molecule $\mathrm{cm}^{-3}$ and $\mathrm{O}_{2}$ concentrations of $(1.1-1.6) \times$ $10^{16}$ molecule $\mathrm{cm}^{-3}$. Helium was used as carrier gas for $\mathrm{NO}_{3}$.
XPS, IR and ToF-SIMS were then used to monitor the oxidation of the monolayer and identify surface products. $\mathrm{H}_{2} \mathrm{O}$ contact angle measurements were used to determine the hydrophilicity of the monolayer.

[15] Note that in our experiments we were using relatively high $\mathrm{NO}_{3}$ concentrations (approximately $1 \times 10^{11}$ molecule $\mathrm{cm}^{-3}$ ), whereas in the atmosphere $\mathrm{NO}_{3}$ concentrations are lower (roughly $1 \times 10^{9}$ molecule $\mathrm{cm}^{-3}$ depending on time and location). In order to extrapolate our results to the atmosphere, we assume that the only important parameter is total number of collisions between $\mathrm{NO}_{3}$ radicals and the surface. This, however, requires verification in future experiments.

\subsection{XPS, IR, ToF-SIMS, and Contact Angle Measurements}

[16] XPS measurements were performed on a Leybold instrument using an achromatic $\mathrm{Al} \mathrm{K} \alpha \mathrm{X}$-ray source at a photon energy of $1486.6 \mathrm{eV}$ and an electron take-off angle of $90^{\circ}$. Infrared measurements were performed with a Bruker grazing angle IR instrument in the wave number range $7000-500 \mathrm{~cm}^{-1}$ (2048 scans per spectrum, $4 \mathrm{~cm}^{-1}$ resolution). Time-of-flight secondary ion mass spectrometry (ToFSIMS) was done using a Physical Electronics, PHI TRIFT II ToF-SIMS instrument with a $15 \mathrm{keV} \mathrm{Ga}^{+}$primary ion beam (mass resolution $\geq 9000$ ). The pulse duration was $5 \mathrm{~ns}$ with a current of $500 \mathrm{pA}$. Sample areas of $100 \times 100 \mu \mathrm{m}^{2}$ were irradiated, total MS acquisition time was $10 \mathrm{~min}$ and negative ion spectra were obtained. The total ion dose was well below static limit. Contact angle estimates were obtained from camera images of a $\mathrm{H}_{2} \mathrm{O}$ droplet (Millipore, $18 \mathrm{M} \Omega$, static) on unreacted monolayers (ODT and UDT) and SAMs exposed to $\mathrm{NO}_{3}$.

\section{Results and Discussion}

\subsection{Reaction of $\mathrm{NO}_{3}$ With an Octadecanethiol (ODT) Monolayer}

\subsubsection{IR Spectroscopy}

[17] Grazing angle IR measurements were performed on ODT SAMs that had been exposed to $\mathrm{NO}_{3}$ radicals. Listed in Table 1 are possible nitrogen species that may form during the $\mathrm{NO}_{3}$ chemistry (in the presence of $\mathrm{O}_{2}$ and $\mathrm{NO}_{2}$ ) and the corresponding IR transition frequencies. For our analysis we only focused on the IR regions from 3000 to $2800 \mathrm{~cm}^{-1}$ and 1700 to $1200 \mathrm{~cm}^{-1}$. The $3000-2800 \mathrm{~cm}^{-1}$ region corresponds to the C-H stretching region. The $1700-1200 \mathrm{~cm}^{-1}$ region covers a frequency range where several of the possible nitrogen species have transitions. We did not include in this analysis the regions above $3000 \mathrm{~cm}^{-1}$, between 2800 and $1700 \mathrm{~cm}^{-1}$ and below $1200 \mathrm{~cm}^{-1}$ because assigning the baseline in these regions was often difficult and subjective owing to large baseline fluctuations, low peak intensities, and interference by water vapor peaks in some areas. Shown in Figure 2 are typical results. $\mathrm{NO}_{3}$ exposures used in this study were $3.6 \times 10^{-5} \mathrm{~atm} \mathrm{sec}$, which is equal to $50 \mathrm{ppt}$ for 8.4 days. $50 \mathrm{ppt}(24 \mathrm{~h}$ average) corresponds roughly to polluted conditions. On the basis of the XPS data shown in Figure 1 the amount of carbon oxidation with this exposure was about $20 \%$. The spectrum shown in Figure 2 corresponds to $\left(\mathrm{I}_{\text {unoxidized }}-\mathrm{I}_{\text {oxidized }}\right) / \mathrm{I}_{\text {unoxidized }}$, where $\mathrm{I}_{\text {oxidized }}$ and $\mathrm{I}_{\text {unoxidized }}$ correspond to the intensity of the reflected light from the oxidized and unoxidized film, respectively. The results from 


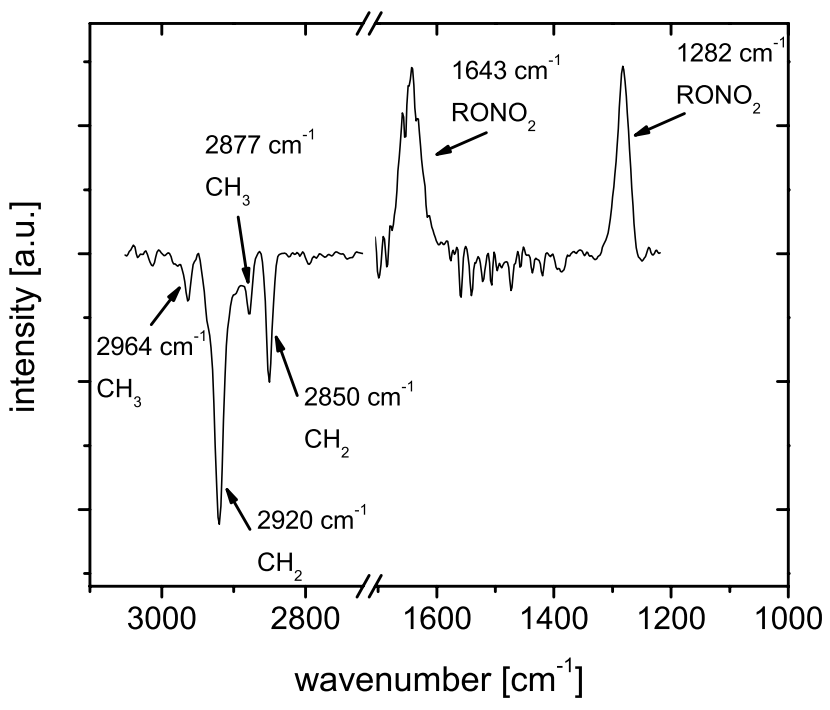

Figure 2. ODT IR spectrum calculated from an ODT sample exposed to $3.6 \times 10^{-5} \mathrm{~atm} \mathrm{sec} \mathrm{of} \mathrm{NO}_{3}$ and an unoxidized ODT SAM as reference sample (see text). Negative peaks correspond to features only present or more prominent in the unexposed ODT SAM; positive peaks show features only present or more prominent in the exposed ODT SAM.

Figure 2 show first that the $\mathrm{NO}_{3}$ reaction led to the disappearance of the $\mathrm{CH}_{3}$ and $\mathrm{CH}_{2}$ groups, which is consistent with the oxidation of the organic chain. Figure 2 also shows the appearance of new peaks at 1645 and $1283 \mathrm{~cm}^{-1}$ after exposure to $\mathrm{NO}_{3}$. The presence of these peaks is consistent with the formation of organonitrates $\left(\mathrm{RONO}_{2}\right)($ see Table 1$)$. Organonitro $\left(\mathrm{RNO}_{2}\right)$ groups, peroxynitrates $\left(\mathrm{ROONO}_{2}\right)$ and peroxyacylnitrate surface species were not identified in the IR data. Peroxynitrates and peroxyacylnitrates are expected to have a short lifetime. Hence, these species may have been lost when transferring the substrates to the analytical instruments for surface analysis.

[18] The observation of organonitrate peaks in the IR spectrum is in contrast to the XPS data by Knopf et al. [2006], which showed very little N(1s) signal. This suggests that the organonitrates decomposed during the XPS measurements. To investigate this further we exposed an ODT monolayer to $\mathrm{NO}_{3}$ (exposure level $=9.06 \times 10^{-5} \mathrm{~atm} \mathrm{sec}$ ). Then we recorded an IR spectrum of the sample, followed by an XPS spectrum, followed by another IR spectrum. In the first IR spectrum negative peaks in the region from 3000 to $2800 \mathrm{~cm}^{-1}$ were observed owing to the disappearance of $\mathrm{CH}_{3}$ and $\mathrm{CH}_{2}$ surface species, and positive peaks at $1645 \mathrm{~cm}^{-1}$ and $1283 \mathrm{~cm}^{-1}$ were observed due to the formation of alkylnitrates, similar to Figure 2. However, in the second IR spectrum (after the XPS measurements) the $1645 \mathrm{~cm}^{-1}$ and $1283 \mathrm{~cm}^{-1}$ peaks were strongly diminished in intensity, while features for $\mathrm{CH}_{3}$ and $\mathrm{CH}_{2}$ remained unchanged. This provides further support that the $\mathrm{N}$-containing functional groups decomposed during XPS analysis. In general, XPS is considered nondestructive, but some damage to sensitive material has been reported before [Laibinis et al., 1991; Ulman, 1995; Wasserman et al., 1989]. A comparison between the average bond energies shows that $\mathrm{O}-\mathrm{N}$ bonds $\left(201 \mathrm{~kJ} \mathrm{~mol}^{-1}\right)$ are much weaker than $\mathrm{C}-\mathrm{O}\left(358 \mathrm{~kJ} \mathrm{~mol}^{-1}\right)$ or $\mathrm{C}=\mathrm{O}\left(799 \mathrm{~kJ} \mathrm{~mol}^{-1}\right)[$ Ebbing, 1993] and therefore organonitrates should be much more prone to decomposition in XPS than the other functional groups expected in our experiments. Alcohols, carbonyl and carboxyl groups have been analyzed successfully by XPS in the past [Briggs and Beamson, 1992; Dicke et al., 2002; Wang et al., 2005] and are not expected to decompose owing to the bond strengths.

\subsubsection{ToF-SIMS Measurements}

[19] ToF-SIMS measurements were also carried out to further confirm the formation of nitrate functional groups. Figure 3 shows negative ion ToF-SIMS spectra of an ODT monolayer prior to exposure to $\mathrm{NO}_{3}$ (Figure 3a) and after exposure to $\mathrm{NO}_{3}$ (Figure $3 \mathrm{~b}$ ). For these studies an exposure of $5.4 \times 10^{-5} \mathrm{~atm} \mathrm{sec}$ (equivalent to $50 \mathrm{ppt} \mathrm{NO}_{3}$ for 12.6 days) was used. On the basis of the XPS data shown in Figure 1, approximately $35 \%$ of the carbon is oxidized with this exposure.

[20] The Figure 3a spectrum, recorded before $\mathrm{NO}_{3}$ exposure, shows mostly $\mathrm{Au}_{\mathrm{x}} \mathrm{S}_{\mathrm{y}}$ clusters and low molecular weight

Table 1. Peak Assignment for IR Spectroscopy of Different Nitrogen Containing Species ${ }^{\mathrm{a}}$

\begin{tabular}{|c|c|c|}
\hline Assignment & $\begin{array}{l}\text { Peak Position } \\
\left(\mathrm{cm}^{-1}\right)\end{array}$ & Reference \\
\hline \multirow[t]{2}{*}{$\mathrm{RNO}_{2}$} & $1580-1540$ & $\begin{array}{l}\text { Allen et al. [1994], Hung et al. [2005], Jang and Kamens [2001], } \\
\text { Lai and Finlayson-Pitts [1991], Tuazon et al. [1999], Williams and Fleming [1989] }\end{array}$ \\
\hline & $1390-1340$ & $\begin{array}{l}\text { [Hung et al. [2005], Jang and Kamens [2001], } \\
\quad \text { Tuazon et al. [1999], Williams and Fleming [1989] }\end{array}$ \\
\hline \multirow[t]{3}{*}{$\mathrm{RONO}_{2}$} & $1666-1600$ & $\begin{array}{l}\text { [Allen et al. [1994], Alvarado et al. }[1999], \text { Atkinson et al. }[1998] \\
\text { Hallquist et al. }[1999], \text { Hung et al. }[2005], \text { Jang and Kamens }[2001], \\
\text { Lai and Finlayson-Pitts [1991], Palen et al. [1992], Tuazon et al. [1999], Williams and Fleming [1989] }\end{array}$ \\
\hline & $1286-1250$ & $\begin{array}{l}\text { Allen et al. [1994], Alvarado et al. [1999], Atkinson et al. [1998], } \\
\text { Cassanelli et al. [2006], Hallquist et al. [1999], Hung et al. [2005], } \\
\text { Palen et al. [1992], Tuazon et al. [1999], Williams and Fleming [1989] }\end{array}$ \\
\hline & $862-843$ & $\begin{array}{l}\text { Allen et al. [1994], Alvarado et al. [1999], Atkinson et al. [1998], } \\
\text { Cassanelli et al. [2006], Hallquist et al. [1999], Hung et al. [2005], Palen et al. [1992], Tuazon et al. [1999] }\end{array}$ \\
\hline \multirow[t]{3}{*}{$\mathrm{ROONO}_{2}$} & $1724-1721$ & Hallquist et al. [1999], Tuazon et al. [1999] \\
\hline & $1298-1296$ & Hallquist et al. [1999], Hung et al. [2005], Tuazon et al. [1999] \\
\hline & $797-789$ & Hallquist et al. [1999], Tuazon et al. [1999] \\
\hline \multirow[t]{4}{*}{ PAN } & $1842-1830$ & Allen et al. [2005], Atkinson et al. [1998] \\
\hline & $1741-1738$ & Allen et al. [2005], Atkinson et al. [1998] \\
\hline & $1302-1300$ & Allen et al. [2005], Atkinson et al. [1998] \\
\hline & 794 & Allen et al. [2005], Atkinson et al. [1998] \\
\hline
\end{tabular}

${ }^{\mathrm{a}} \mathrm{R}$, alkyl chain; PAN, peroxyacetylnitrate. Typical ranges of wave numbers $\left(\mathrm{cm}^{-1}\right)$ and references are provided. 

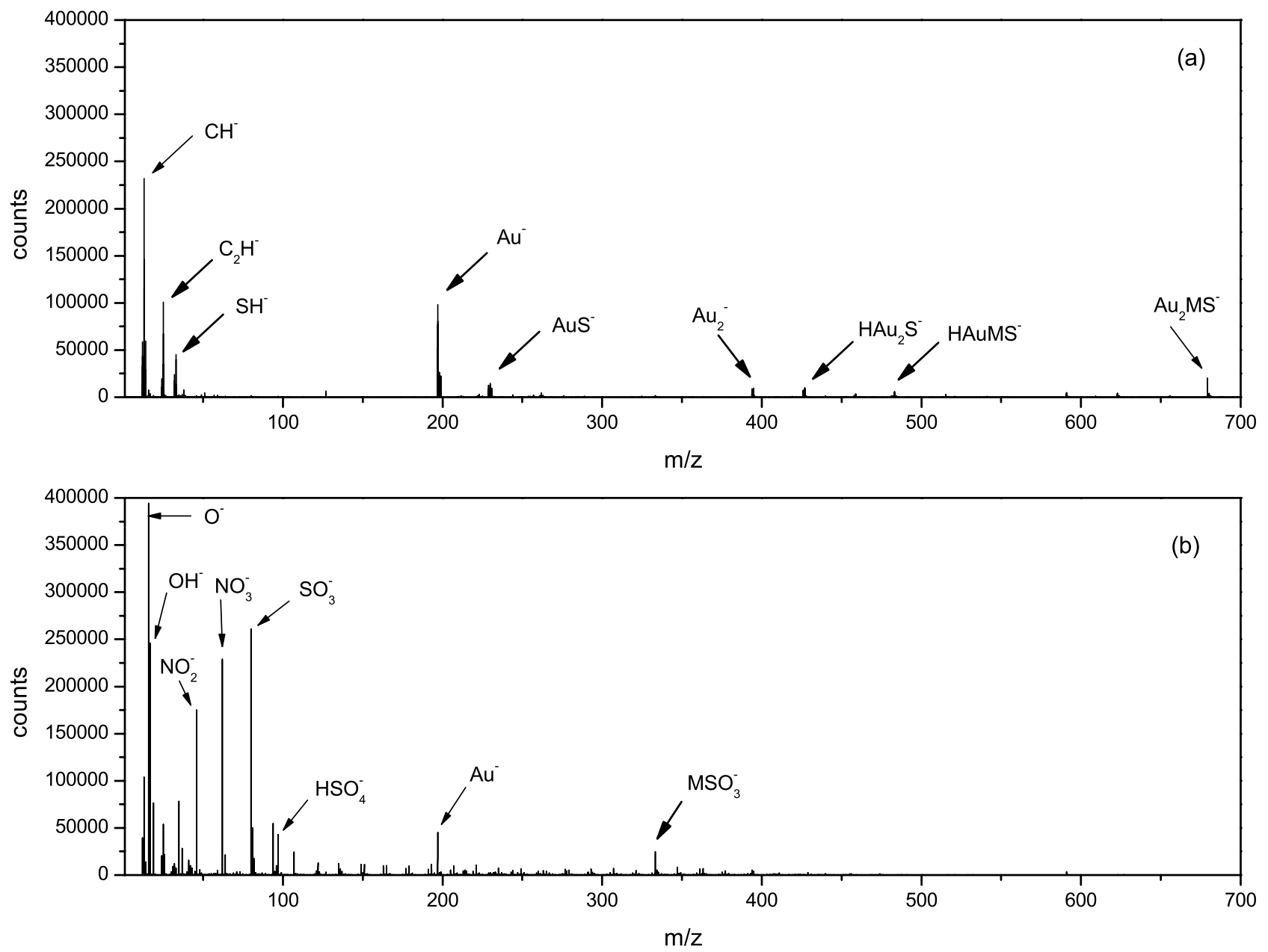

Figure 3. Negative ion ToF-SIMS spectra of ODT on gold in the $\mathrm{m} / \mathrm{z}$ 1-700 region. (a) Spectrum was obtained on an ODT sample without $\mathrm{NO}_{3}$ exposure. (b) Spectrum was obtained after an $\mathrm{NO}_{3}$ exposure of $5.4 \times 10^{-5}$ atm sec (equivalent to $50 \mathrm{ppt} \mathrm{NO}_{3}$ for 12.6 days).

fragments of the alkanethiol chains $\left(\mathrm{C}^{-}, \mathrm{CH}^{-}, \mathrm{C}_{2} \mathrm{H}^{-}, \mathrm{S}^{-}\right.$, $\mathrm{SH}^{-}$), but also characteristic peaks for ODT. These peaks included the whole molecule of ODT and are labeled "MS" in Figure 3 with " $\mathrm{M}$ " meaning $\mathrm{C}_{18} \mathrm{H}_{37}$. The observed peaks agreed well with those observed in previous ToF-SIMS measurements of alkanethiol SAMs on gold performed by Offord et al. [1994], Sun and Gardella [2002], and Sohn et al. [2004].

[21] Comparisons of ODT spectra in Figures $3 a$ and $3 b$ showed that after $\mathrm{NO}_{3}$ exposure, peaks characteristic of the unoxidized hydrocarbon SAMs $\left(\mathrm{C}^{-}, \mathrm{CH}^{-}, \mathrm{C}_{2} \mathrm{H}^{-}, \mathrm{S}^{-}, \mathrm{SH}^{-}\right.$, $\mathrm{HAuMS}^{-}$, and $\mathrm{Au}_{2} \mathrm{MS}^{-}$) decreased or disappeared. New peaks of high intensities formed in the $\mathrm{m} / \mathrm{z}$ region $<100 \mathrm{amu}$, which can be attributed to $\mathrm{O}^{-}, \mathrm{OH}^{-}, \mathrm{NO}_{2}^{-}, \mathrm{NO}_{3}^{-}, \mathrm{SO}_{3}^{-}$, and $\mathrm{HSO}_{4}^{-}$. Furthermore, a large number of additional peaks emerged in the $\mathrm{m} / \mathrm{z}$ region $>100 \mathrm{amu}$, but with smaller intensities. These are most likely due to oxidized ODT molecules that subsequently fragmented during the sputtering process. Owing to the high number of possible fragments in these long chain hydrocarbons, the wide variety of different oxidation levels and the variety of different oxidation products, it was not possible to identify these products unambiguously.
[22] The identification of $\mathrm{NO}_{2}^{-}$and $\mathrm{NO}_{3}^{-}$peaks in ToF-SIMS confirmed the formation of nitrogen containing species on the surface, and these peaks are also consistent with the formation of organonitrates, which fragment to $\mathrm{NO}_{2}^{-}$and $\mathrm{NO}_{3}^{-}$ during the sputtering process.

[23] The combined evidence for the presence of organonitrates found in IR and ToF-SIMS clearly showed that these compounds were formed during reaction of ODT with $\mathrm{NO}_{3}$ but were not stable in XPS analysis.

[24] The Figure $3 \mathrm{~b}$ spectrum also shows peaks due to $\mathrm{SO}_{3}^{-}$ and $\mathrm{HSO}_{4}^{-}$. Oxidized sulfur likely results from oxidization of the sulfur group in the monolayer by $\mathrm{NO}_{3}$ at large exposures. This is consistent with previous XPS results that also showed oxidation of the sulfur group at $\mathrm{NO}_{3}$ exposures greater than $3 \times 10^{-5}$ atm sec [Knopf et al., 2006].

\subsubsection{Contact Angle Measurements}

[25] Contact angles of $\mathrm{H}_{2} \mathrm{O}$ droplets on unexposed and $\mathrm{NO}_{3}$ exposed ODT monolayers were obtained using camera images. The initial contact angle determined for ODT before $\mathrm{NO}_{3}$ exposure was $101^{\circ} \pm 4^{\circ}$ (error represents one standard deviation). Reported literature values for different long chain alkane monolayers $\left(\mathrm{C}_{8}-\mathrm{C}_{18}\right)$ range from $93^{\circ}$ to $119^{\circ}$ [Bain et al., 1989; Bertram et al., 2001; Dubowski et al., 2004; Inman 


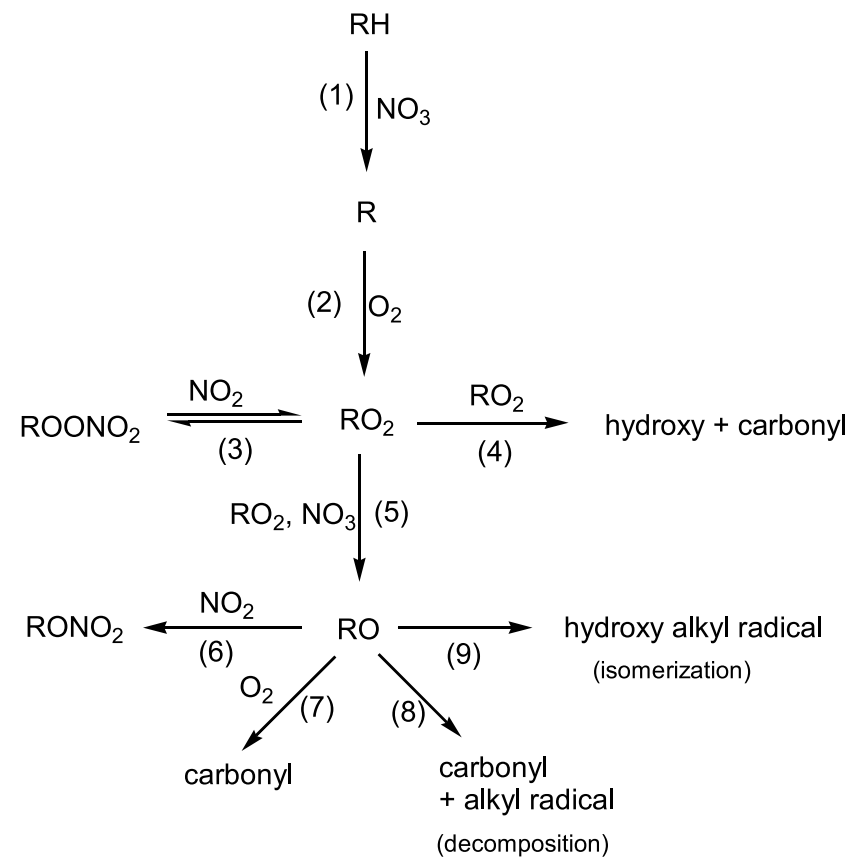

Figure 4. Proposed reaction mechanism for an alkane surface with $\mathrm{NO}_{3}$ in the presence of $\mathrm{NO}_{2}$ and $\mathrm{O}_{2}$ based on gas-phase chemistry.

et al., 2004; Offord et al., 1994; Owens et al., 2004; Paz et al., 1992; Robinson et al., 1995; Rudich et al., 2000; Thomas et al., 2001; Wasserman et al., 1989]. These numbers show that our contact angle for ODT is in general agreement with literature values.

[26] ODT samples were exposed to $9.06 \times 10^{-5} \mathrm{~atm} \mathrm{sec}$ $\mathrm{NO}_{3}$ (equivalent to $50 \mathrm{ppt}$ for 21 days). This exposure can be seen as an extreme limit of aerosol exposure under polluted conditions. After this exposure, the contact angle on ODT was $60^{\circ} \pm 6^{\circ}$, a decrease by approximately $41^{\circ}$. This result is consistent with the monolayers becoming more hydrophilic owing to oxidation. Previous studies investigating changes in $\mathrm{H}_{2} \mathrm{O}$ contact angles $(\theta)$ on hydrocarbon monolayers $\left(\mathrm{C}_{8}-\right.$ $\mathrm{C}_{20}$ ) after exposure to gas-phase reactants reported a very broad range of data for alkanes: after $\mathrm{F}$ radical exposure $\theta=$ $82^{\circ}$ [Robinson et al., 1995], after $\mathrm{O}_{3}$ exposure $\theta=71^{\circ}$ and $99^{\circ}$ [Owens et al., 2004; Thomas et al., 2001], after $\mathrm{OH}$ exposure $\theta=10^{\circ}$ [Bertram et al., 2001], and after O exposure $\theta=\sim 35-$ $45^{\circ}$ [Paz et al., 1992]. Part of the variability is likely due to the different exposure levels used in these experiments and also to different condensed phase products formed (e.g., hydroxyl groups versus carbonyl groups).

[27] To put our values in an atmospheric context, we converted our contact angle results into cloud condensation nucleation activities. On the basis of data presented by Pruppacher and Klett [1997], an insoluble $200 \mathrm{~nm}$ (diameter) particle with $\theta=101^{\circ}$ will have a critical supersaturation $\left(\mathrm{S}_{\text {crit }}=\mathrm{RH}-100 \%\right)$ for water nucleation of $>150 \%$. In contrast, an insoluble $200 \mathrm{~nm}$ particle with $\theta=60^{\circ}$ will have a critical supersaturation of approximately $100 \%$. This shows that the oxidation by $\mathrm{NO}_{3}$ radicals can decrease the critical supersaturation required for water nucleation. However, even after oxidation, the $S_{\text {crit }}$ is still much larger than $\mathrm{S}_{\text {crit }}$ for water soluble particles. For example, $\mathrm{S}_{\mathrm{cit}}$ for a
$200 \mathrm{~nm}$ ammonium sulfate particle is less than $0.1 \%$ [Seinfeld and Pandis, 2006]. Also, typical values of supersaturations found in clouds are between about 0.2 and $2 \%$ [Finlayson-Pitts and Pitts, 2000].

\subsubsection{Proposed Reaction Mechanism}

[28] Shown in Figure 4 is the proposed mechanism for oxidation of an alkane monolayer by $\mathrm{NO}_{3}$ radicals in the presence of $\mathrm{O}_{2}$ and $\mathrm{NO}_{2}$ based on gas-phase chemistry. We use this as a starting point to discuss the previous XPS data from Knopf et al. [2006] and the current IR and ToF-SIMS data.

[29] As a reminder, XPS showed limited volatilization (i.e., loss of the carbon chain), and the formation of (1) C-O groups, (2) ketones or aldehydes, and (3) carboxylic groups. The IR spectra and ToF-SIMS showed the formation of organonitrates.

[30] The initial reaction step (1) in the oxidation process is the abstraction of a hydrogen atom from a methyl or methylene group of the alkyl chain to form $\mathrm{HNO}_{3}$ and an alkyl radical. The second reaction step is the transformation of an alkyl radical into a peroxy radical in the presence of $\mathrm{O}_{2}$ [Atkinson, 1997]. In the presence of $\mathrm{NO}_{2}$, peroxynitrates may form which may subsequently thermally decompose back to the reactants (step 3) [Atkinson, 1997]. Hence peroxynitrates represent a temporary reservoir of $\mathrm{NO}_{2}$. The peroxy radical can also react with $\mathrm{NO}_{3}$ to form an alkoxy radical, $\mathrm{NO}_{2}$, and $\mathrm{O}_{2}$ (step 5). Alternatively, the peroxy radical can undergo self reaction, leading to the formation of alkoxy radicals and $\mathrm{O}_{2}$ (step 5) or an alcohol and carbonyl (step 4) [Atkinson, 1997]. If the alkoxy radical forms, it can decompose by scission of a C-C bond (step 8), or can undergo isomerization to form a hydroxyl alkyl radical (step 9). Alternatively the alkoxy radical can react with $\mathrm{NO}_{2}$ to form alkylnitrates (step 6) or react with $\mathrm{O}_{2}$ to form ketones or aldehydes (step 7) [Atkinson, 1997].

[31] The XPS data suggest that decomposition by scission of a $\mathrm{C}-\mathrm{C}$ bond is of minor importance (step 8). The presence of C-O, ketones, and aldehydes can be explained by step 4, step 7 or step 9. Carboxylic functional groups observed in XPS spectra are probably due to $\mathrm{C}(=\mathrm{O}) \mathrm{O}$ formed in secondary reactions, for example, oxidation of aldehydes to acids (as reported by George et al. [2007]). The new results in this manuscript (based on IR and ToF-SIMS data) show that organic nitrates are also a significant product of the heterogeneous oxidation. Organonitrates can be formed by step 6 . Alternatively it has been suggested that organoperoxynitrates can decompose in the condensed phase to form organonitrates or carbonyls [Docherty and Ziemann, 2006]. This pathway (not shown in Figure 4) may also be important in our monolayer studies for the production of organonitrates.

[32] The identification of organonitrates in our oxidation studies may be important for a few reasons: first, the formation of organonitrates in our experiment may explain why we did not see significant decomposition of the carbon chains in our recent studies with $\mathrm{NO}_{3}$ radicals. In our previous study we showed that $\mathrm{NO}_{3}$ (in the presence of $\mathrm{O}_{2}$ and $\mathrm{NO}_{2}$ ) does not rapidly decompose an alkane monolayer by scission of a $\mathrm{C}-\mathrm{C}$ bond: even under extremely polluted conditions, the maximum loss of the organic layer was only $10 \%$ [Knopf et al., 2006]. This is consistent with our current studies that show that the formation of organonitrates is a significant pathway. Formation of organonitrates removes $\mathrm{RO}_{2}$ and/or $\mathrm{RO}$ species 
from the system, and hence will reduce the importance of the decomposition channel. Possibly this is one of the differences between our work with $\mathrm{NO}_{3}$ and alkane monolayers and the recent studies with $\mathrm{OH}$ and alkane SAMs where significant decomposition was observed.

[33] Second, the results suggest that perhaps under certain atmospheric conditions, radical-organic reactions may be a source of condensed phase organonitrates. It is well known that condensation of gas phase species is an important source of condensed phase organonitrates. Also another possible source of particle-bound organonitrates is condensed phase photochemistry [Karagulian et al., 2008]. Perhaps under certain conditions of high $\mathrm{NO}_{3}$ and $\mathrm{NO}_{2}$ concentrations the formation of condensed phase organonitrates by radical-organic reactions may also contribute. Field measurements exploring this topic would be interesting.

[34] Third, our results may have implications for condensed phase $\mathrm{OH}$-organic reactions as well. Under many atmospheric conditions, $\mathrm{NO}_{2}$ concentrations are high. Perhaps for these situations, organonitrates will also form by a similar mechanism to the mechanism in our experiments (either $\mathrm{RO}+\mathrm{NO}_{2}$ or $\mathrm{RO}_{2}+\mathrm{NO}_{2}$ to form $\mathrm{RO}_{2} \mathrm{NO}_{2}$ followed by decomposition to $\mathrm{RONO}_{2}$ ) and limit the importance of the decomposition channel (step 8 in Figure 4) in the $\mathrm{OH}$-organic reaction. However, Molina et al. [2004] studied the oxidation of an alkane monolayer by $\mathrm{OH}$ in the presence of $\mathrm{NO}_{\mathrm{x}} / \mathrm{O}_{2} /$ $\mathrm{H}_{2} \mathrm{O}$ in various proportions and they observed significant decomposition of the monolayer. This suggests that the $\mathrm{OH}$-organic reaction mechanism is less susceptible to the presence of $\mathrm{NO}_{2}$.

\subsection{Reaction of $\mathrm{NO}_{3}$ With Undecenethiol (UDT): A Terminal Alkene SAM}

\subsubsection{Reactive Uptake Coefficient of $\mathrm{NO}_{3}$ on an Unoxidized UDT SAM}

[35] The $\gamma$ value for a UDT SAM was determined to be $3.4 \times 10^{-2}\left(+4.4 \times 10^{-2} /-1.8 \times 10^{-2}\right)$ (the uncertainty reported corresponds to the $95 \%$ confidence interval and an uncertainty in the diffusion coefficients of $\mathrm{NO}_{3}$ in $\mathrm{He}$ and $\mathrm{O}_{2}$ of $15 \%$ ). In comparison, the value determined for ODT was $(8.8 \pm 1.0) \times 10^{-4}$ [Knopf et al., 2006], a factor of approximately 39 less. This enhancement of UDT reactivity compared to ODT reactivity is in agreement with the enhancement observed for reaction rate constants of different gas-phase reactions of alkanes and alkenes with $\mathrm{NO}_{3}$. For example $\mathrm{k}_{\text {propene }} / \mathrm{k}_{\text {propane }}=18, \mathrm{k}_{1 \text {-butene }} / \mathrm{k}_{\mathrm{n} \text {-butane }}=305$, $\mathrm{k}_{\text {cyclohexene }} / \mathrm{k}_{\text {cyclohexane }}=237$, where $\mathrm{k}$ represents different gas-phase rate constants for $\mathrm{NO}_{3}$ reactions [Atkinson, 1997; Finlayson-Pitts and Pitts, 2000].

[36] The $\gamma$ value of the terminal alkene UDT obtained in this study is higher than the values obtained by Moise et al. [2002] using liquid and solid alkene bulk films. Moise et al. [2002] measured $(1.6 \pm 0.3) \times 10^{-3}$ and $(1.4 \pm 0.1) \times 10^{-3}$ for liquid and solid 1-octadecene films; $(2.3 \pm 0.9) \times 10^{-3}$ and $(1.8 \pm 0.3) \times 10^{-3}$ for liquid and solid 1 -hexadecene films; $(5.8 \pm 2.0) \times 10^{-3}$ and $(5.2 \pm 2.0) \times 10^{-3}$ for liquid and solid 7-tetradecene films, respectively. A possible reason for this difference may be the location of the double bond at the interface. In our experiments the double bond is located at the outermost two carbon atoms and is probably more easily accessible by $\mathrm{NO}_{3}$ radicals than double bonds in a liquid or bulk solid. Vieceli et al. [2004], recently studied the structure of liquid 1-tetradecene $\left(\mathrm{C}_{14}\right.$ alkene with a terminal double bond) and a 1-octenethiol SAM using molecular dynamics simulations. They showed that at the air-liquid interface the molecular orientation becomes perpendicular to the interface normal rather than random. Also these authors reported the percentage of the total accessible surface area that is due to double bonds as 28.5 and $99.7 \%$ for liquid 1-tetradecene and the terminal-alkene SAM, respectively. This trend is consistent with the difference observed between our study and the studies by Moise et al. [2002].

[37] Another possible reason for the difference between our results and the results by Moise et al. [2002] may be the $\mathrm{NO}_{3}$ concentrations used in the different experiments. Moise et al. [2002] used a slightly higher concentration of $\mathrm{NO}_{3}$. They also used a rotating flow reactor which replenishes the surfaces of the liquid and prevents the surface from being rapidly oxidized.

[38] Table 2 shows a summary of studies on heterogeneous reactions of different gas-phase oxidants with terminal alkene monolayers. Reactive uptake coefficients, $\gamma$, and average atmospheric concentrations for each oxidant are reported. Direct comparison of $\gamma$ values for each oxidant is of minor atmospheric relevance since the concentration of each oxidant is different in the atmosphere. Therefore the last column in Table 2 shows the product of $\gamma$ and the average atmospheric concentrations of the gas-phase oxidants. These numbers are more relevant parameters for assessing the importance of the various gas-phase species to atmospheric oxidation since the number of molecules lost to an organic surface should be proportional to $\gamma \times$ concentration. The most important process will generally be the process with the largest $\gamma \times$ [reactant concentration] and therefore the highest oxidative power. The abundance of $\mathrm{NO}_{3}$ in the atmosphere is highly variable, with a high spatial and seasonal variability. For these calculations we use $\mathrm{NO}_{3}$ concentrations of $50 \mathrm{ppt}$ and $5 \mathrm{ppt}$ to roughly represent polluted urban and rural conditions [Atkinson et al., 1986; Finlayson-Pitts and Pitts, 2000; Geyer et al., 2001]. However, keep in mind $\mathrm{NO}_{3}$ concentrations vary significantly in urban and rural conditions. As can be seen from Table 2, the oxidative power of $\mathrm{NO}_{3}$ is significantly higher than that of $\mathrm{OH}, \mathrm{Cl}$, and $\mathrm{Br}$. Only $\mathrm{O}_{3}$ is of equal importance to $\mathrm{NO}_{3}$ owing to its much higher tropospheric concentrations.

[39] Using the reactive uptake coefficient determined in this study and the equation presented by Gross and Bertram [2008] and Moise and Rudich [2001], we can calculate an average lifetime of an alkene monolayer at the interface of an aerosol particle in the atmosphere. Assuming an $\mathrm{NO}_{3}$ concentration of $50 \mathrm{ppt}$, we obtain a value of $22.6 \mathrm{~min}$. This shows that the lifetime is short in polluted environments and that in regions where $\mathrm{NO}_{3}$ concentrations are high, surface concentrations of alkenes are expected to be low. A similar conclusion was reached by Moise and Rudich [2001] using reactive uptake coefficients determined on bulk liquid and solid alkene films.

\subsubsection{Measurements of the Reactive Uptake of $\mathrm{NO}_{3}$ as a Function of Exposure Time}

[40] Measurements of the reactive uptake coefficient as a function of time were carried out to determine if the surfaces were catalytic (i.e., a reaction takes place at the surface but the surface is not an active participant) or if the reaction rate 
Table 2. Reactive Uptake Coefficients of Different Gas-Phase Oxidants on Terminal Alkene Monolayers, Average Atmospheric Concentrations of the Gas-Phase Species, and Calculated Oxidative Power ${ }^{\mathrm{a}}$

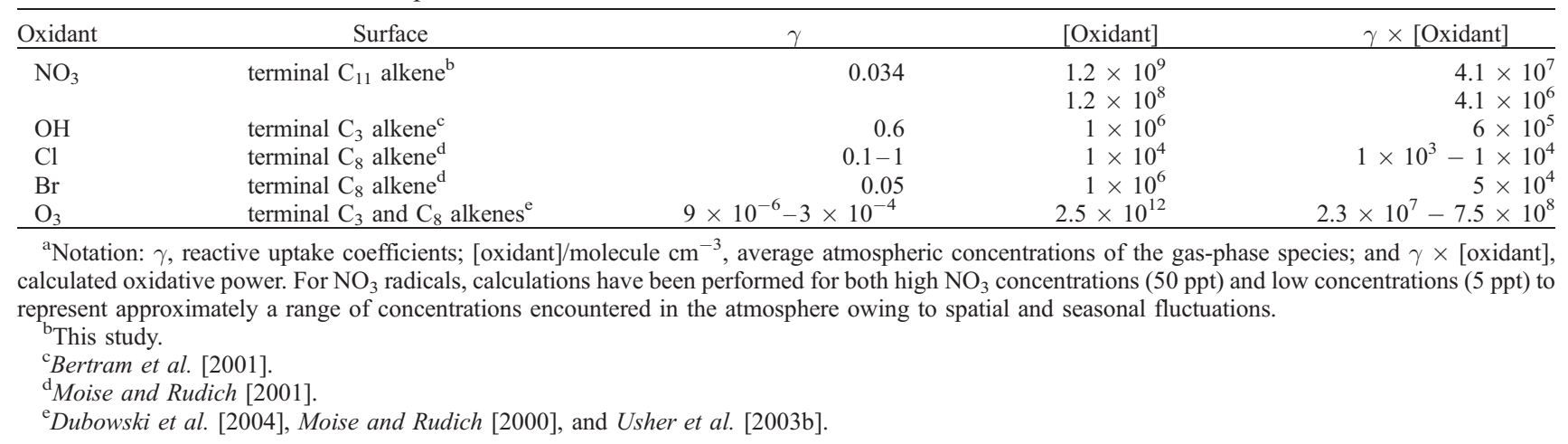

decreased with time owing to oxidation of the monolayer. For these measurements an $\mathrm{NO}_{3}$ concentration of $1.0 \times 10^{11}$ molecule $\mathrm{cm}^{-3}$ was used. The change in $\gamma$ with exposure to $\mathrm{NO}_{3}$ is shown in Figure 5. The initial fast uptake coefficient is most likely due to a fast reaction with the double bond. Once the double bond was oxidized, the uptake coefficient reached a value consistent with the uptake on an alkane monolayer. The exposure at which the reactive uptake reached a near steady state value is consistent with the time it would take to oxidize all the alkene functional groups on the surface, based on calculations presented by Bertram et al. [2001].

[41] Next XPS, IR and ToF-SIMS studies of the reaction of $\mathrm{NO}_{3}$ with alkene monolayers are presented. The purpose of these measurements is to identify surface products and determine the mechanism for the oxidation of the double bond. All these experiments were carried out using exposures less than $2 \times 10^{-5} \mathrm{~atm} \mathrm{sec}$, which is significantly less than the exposures used in our previous alkane SAM studies. As shown in Figure 1, an alkane monolayer is hardly oxidized at exposures less than $2 \times 10^{-5}$ atm sec. Using these low exposure levels, the reaction should be mostly confined to the double bond.

\subsubsection{X-ray Photoelectron Spectroscopy}

[42] XPS measurements of alkene monolayers were carried out as a function of $\mathrm{NO}_{3}$ exposure (ranging from 0 to $1.8 \times 10^{-5} \mathrm{~atm} \mathrm{sec}$, equivalent to $0-4.2$ days at $50 \mathrm{ppt}$ $\mathrm{NO}_{3}$ ). Figure 6 shows the $\mathrm{C}(1 \mathrm{~s})$ region of the XPS spectra obtained using three different $\mathrm{NO}_{3}$ exposures ranging from 0 to $9.1 \times 10^{-6} \mathrm{~atm} \mathrm{sec}$ (equivalent to $50 \mathrm{ppt}$ for $50 \mathrm{~h}$ ). For the unexposed sample only one peak at $285 \mathrm{eV}$ was observed. This peak is due to vinyl or methylene functional groups. After exposure to $\mathrm{NO}_{3}$, the main peak at about $285 \mathrm{eV}$ remained, but a shoulder was observed at higher energies within the $C(1 \mathrm{~s})$ region indicating the oxidation of the organic surface. We fit the total $\mathrm{C}(1 \mathrm{~s})$ region with four overlapping Gaussian-Lorentzian peaks, similar to our previous studies of alkane monolayers. The peaks used in the fit were centered at approx. $285 \mathrm{eV}, 286.5 \mathrm{eV}, 288 \mathrm{eV}$, and $289.5 \mathrm{eV}$. The peaks at energies above $285 \mathrm{eV}$ represent oxidized C species (consistent with $\mathrm{C}-\mathrm{O}$, aldehyde/ketone, and carboxylic groups, respectively).

[43] To determine the fraction of carbon oxidized as a function of exposure time, we calculated the atomic ratio of oxidized carbon $\left(\mathrm{C}_{\mathrm{ox}}\right.$, three peaks at higher binding energy) to the total carbon peak area $\left(\mathrm{C}_{\text {total }}\right)$. Figure $7 \mathrm{c}$ shows these ratios for $\mathrm{NO}_{3}$ exposures of $0-1.8 \times 10^{-5}$ atm sec. The error bars (which represent $\pm 2 \sigma$ ) were derived from four different UDT SAMs on gold-coated Si wafers exposed to the same amount of $\mathrm{NO}_{3}$. As can be seen, after exposures of only $2.0 \times$ $10^{-7} \mathrm{~atm}$ sec (equivalent to $1.1 \mathrm{~h}$ at $50 \mathrm{ppt} \mathrm{NO}_{3}$ ), approximately $12 \%$ of the $\mathrm{C}(1 \mathrm{~s})$ signal corresponded to oxidized carbon.

[44] Figure $7 \mathrm{~b}$ shows the increase in $\mathrm{O}(1 \mathrm{~s})$ due to increasing $\mathrm{NO}_{3}$ exposure. The trend observed is qualitatively the same as for $\mathrm{C}_{\mathrm{ox}} / \mathrm{C}_{\text {total }}$ in Figure $7 \mathrm{c}$. As with $\mathrm{C}_{\mathrm{ox}} / \mathrm{C}_{\text {total }}$, it is observed that for $\mathrm{O} / \mathrm{C}$ after longer exposures $(1.2 \times$ $\left.10^{-6}-1.8 \times 10^{-5} \mathrm{~atm} \mathrm{sec}\right)$ the reaction slowed down and $\mathrm{O} / \mathrm{C}$ increased with a smaller slope than in the initial stage of oxidation.

[45] We also exposed the monolayers to $\mathrm{O}_{2}$ and $\mathrm{NO}_{2}$, in the absence of $\mathrm{NO}_{3}$. After exposure to just these species (using concentrations greater than those used in the $\mathrm{NO}_{3}$ experiments) the $\mathrm{C}_{\mathrm{ox}} / \mathrm{C}_{\text {total }}$ atomic ratio and $\mathrm{O} / \mathrm{C}$ atomic ratio were

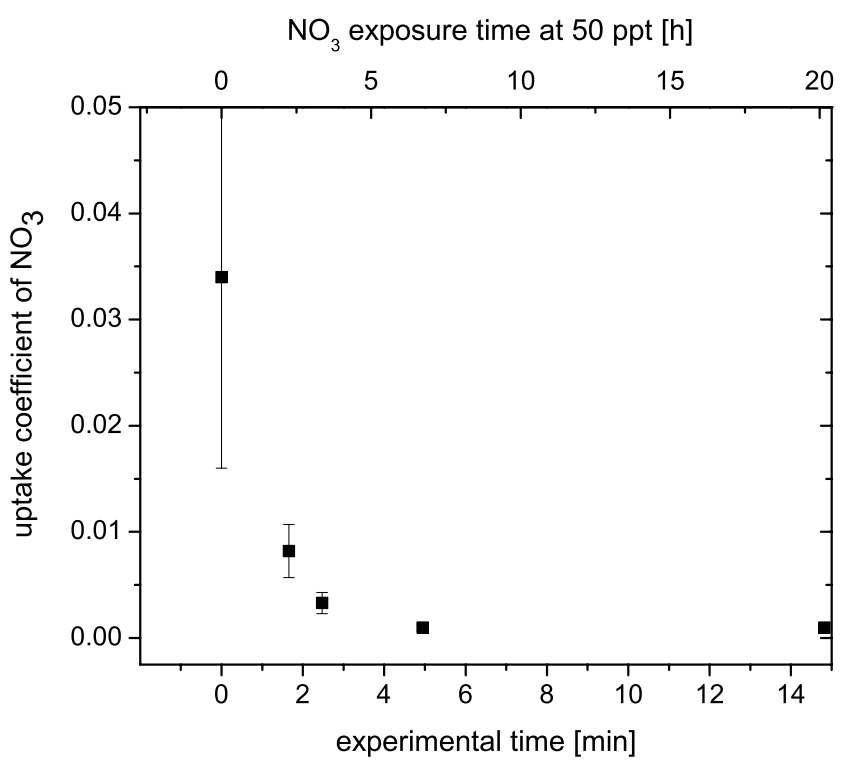

Figure 5. Changes in the reactive uptake coefficient $\gamma$ with increasing $\mathrm{NO}_{3}$ exposure of a UDT SAM. Bottom $x$ axis corresponds to actual time of the experiment $(\mathrm{min})$ (at an $\mathrm{NO}_{3}$ concentration of $1.0 \times 10^{11}$ molecule $\mathrm{cm}^{-3}$ ), and top $x$ axis shows the corresponding total $\mathrm{NO}_{3}$ exposure time (hours) of the SAM at an atmospheric concentration of $50 \mathrm{ppt}$. 


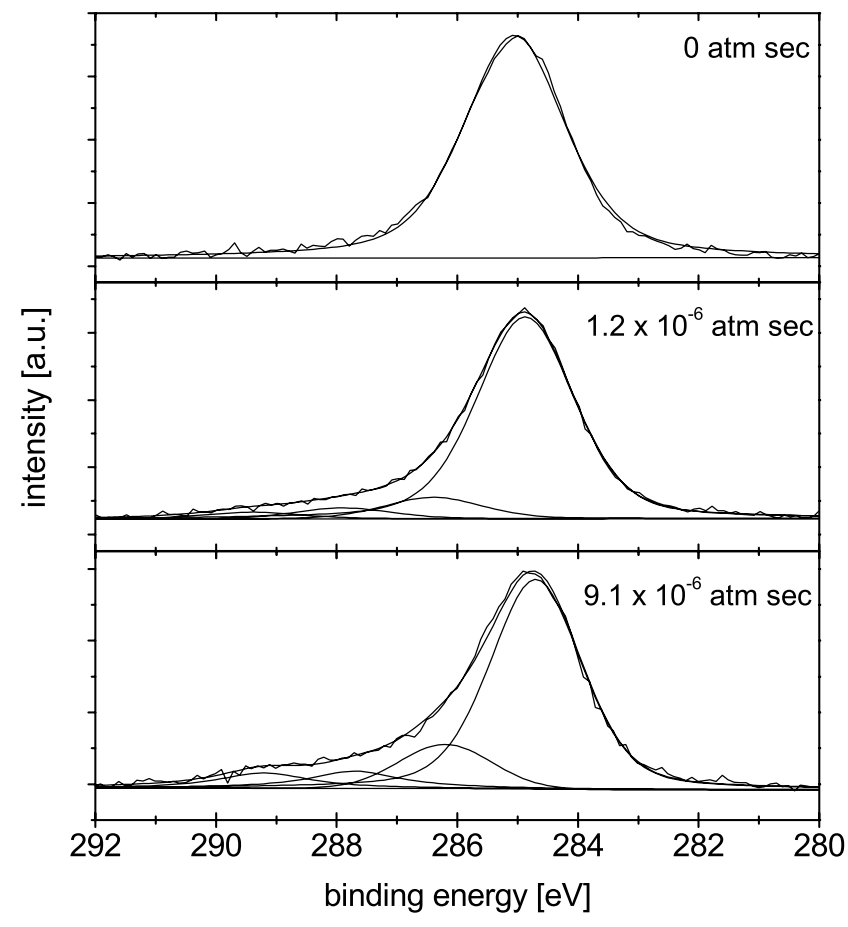

Figure 6. XPS spectra of the $\mathrm{C}(1 \mathrm{~s})$ region for a UDT monolayer (top) before exposure to $\mathrm{NO}_{3}(0 \mathrm{~atm} \mathrm{sec})$ and after exposures of (middle) $1.2 \times 10^{-6}$ atm sec (equivalent to $50 \mathrm{ppt}$ for $6.7 \mathrm{~h}$ ) and (bottom) $9.1 \times 10^{-5} \mathrm{~atm} \mathrm{sec}$ (equivalent to $50 \mathrm{ppt}$ for $50 \mathrm{~h}$ ).

within the error limits for the unexposed sample shown in Figure 7.

[46] To assess the amount of decomposition of the UDT SAM, we plotted the atomic ratio of the total integrated $\mathrm{C}(1 \mathrm{~s})$ signal to the total $\mathrm{Au}(4 \mathrm{f})$ signal intensity $(\mathrm{C} / \mathrm{Au}$ ) (Figure $7 \mathrm{~d}$ ). No significant changes of this ratio could be observed within experimental certainty. However, owing to the large uncertainties, we can only conclude that less than $21 \%$ of the surface volatilized during the longest exposure experiments. As detachment of the carbon chain is also possible owing to oxidation of the sulfur head group, $21 \%$ should be considered an upper limit to the amount of carbon loss due to $\mathrm{C}-\mathrm{C}$ bond scission.

[47] Monitoring the $\mathrm{S}(2 \mathrm{p})$ signal of UDT SAMs after exposure to $\mathrm{NO}_{3}$ showed only unoxidized sulfur (peak maximum at $163.1 \pm 0.2 \mathrm{eV}$ ) for exposures $\leq 1.2 \times 10^{-6} \mathrm{~atm} \mathrm{sec}$ and both unoxidized sulfur (peak maximum at $163.1 \pm 0.2 \mathrm{eV}$ ) and oxidized sulfur (peak maximum at $168.0 \pm 0.2 \mathrm{eV}$ ) for exposures $\geq 9.1 \times 10^{-6} \mathrm{~atm} \mathrm{sec}$.

[48] $\mathrm{N}(1 \mathrm{~s})$ signals were below detection limit in all measurements of exposed and unexposed UDT SAMs. However, the nitrogen species may have formed during the oxidation chemistry but decomposed during XPS measurements, similar to the alkane monolayer experiments. To determine if nitrogen species were formed in these reactions, we carried out IR and ToF-SIMS measurements (see below).

[49] To investigate the behavior of UDT after long exposures to $\mathrm{NO}_{3}$ radicals, we also performed a few experiments with large $\mathrm{NO}_{3}$ exposures. After an exposure of $4.5 \times$ $10^{-5} \mathrm{~atm}$ sec the monolayers reached oxidized $\mathrm{C}$ fractions $\left(\mathrm{C}_{\mathrm{ox}} / \mathrm{C}_{\text {total }}\right)$ of $0.37 \%$, and an $\mathrm{O} / \mathrm{C}$ ratio of $0.42 \%$ (data not

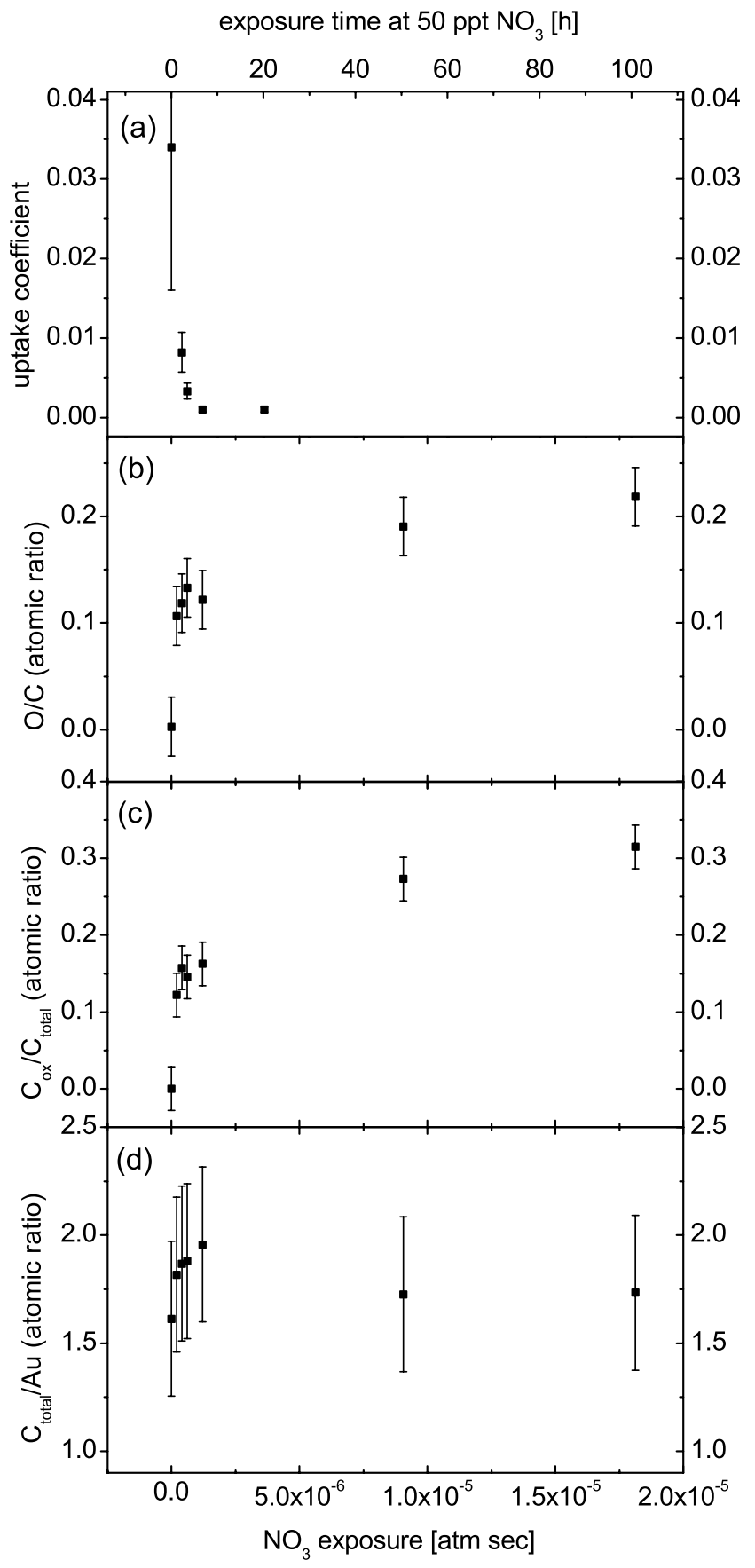

Figure 7. Summary of processing study and XPS results for UDT. (a) Changes in $\gamma$ with increasing $\mathrm{NO}_{3}$ exposure. Changes in atomic ratios obtained in XPS as a function of $\mathrm{NO}_{3}$ exposure for (b) atomic ratio of total oxygen, $\mathrm{O}$, to total carbon, $\mathrm{C}$; (c) atomic ratio of oxidized carbon, $\mathrm{C}_{\mathrm{ox}}$, to total carbon, $\mathrm{C}_{\text {total }}$; and (d) atomic ratio of total carbon, $\mathrm{C}_{\text {total }}$, to total gold, Au. The two scales on the top and bottom $x$ axes are valid for Figures $7 \mathrm{a}-7 \mathrm{~d}$ and provide information on $\mathrm{NO}_{3}$ exposure levels in atm sec (bottom axis) and in total exposure time (hours) at an atmospheric $\mathrm{NO}_{3}$ concentration of $50 \mathrm{ppt}$ (top axis). 


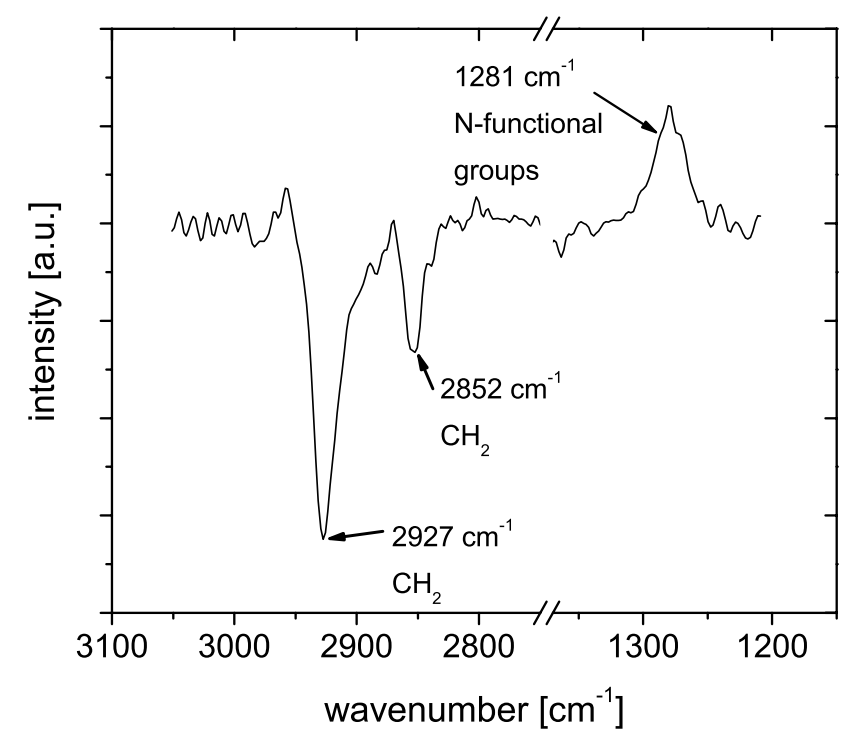

Figure 8. UDT IR spectrum calculated from an UDT sample exposed to $1.21 \times 10^{-6} \mathrm{~atm} \mathrm{sec}$ of $\mathrm{NO}_{3}(50 \mathrm{ppt}$ for $6.7 \mathrm{~h})$ and an unoxidized UDT SAM as reference sample (see text). Negative peaks correspond to features only present or more prominent in the unexposed UDT SAM; positive peaks show features only present or more prominent in the exposed UDT SAM.

shown). These values are similar to the values obtained on ODT monolayers after long $\mathrm{NO}_{3}$ exposures.

\subsubsection{IR Spectroscopy}

[50] First, spectra were taken of an unexposed UDT sample with perdeuterated ODT as reference to confirm the presence of methylene groups in the original UDT SAMs (data not shown). Then IR measurements were performed on samples that had been exposed to $\mathrm{NO}_{3}$. For this analysis we only focused on the IR regions from 3000 to $2800 \mathrm{~cm}^{-1}$ and 1370 to $1200 \mathrm{~cm}^{-1}$. The wavelength range used in these experiments is slightly smaller than the range used in the alkane monolayers experiments. This is because the signal to noise is smaller in the alkene experiments owing to the low $\mathrm{NO}_{3}$ exposures and smaller degree of oxidation of the films. The spectrum shown in Figure 8 was obtained the same way as Figure 2 for ODT. An exposure level of $1.21 \times 10^{-6} \mathrm{~atm} \mathrm{sec}$ $(50 \mathrm{ppt}$ for $6.7 \mathrm{~h}$ ) was used in this experiment. As with ODT, $\mathrm{NO}_{3}$ exposure of UDT resulted in negative peaks in the range $3000-2800 \mathrm{~cm}^{-1}$ due to the decrease of the symmetric and asymmetric stretching modes of $\mathrm{CH}_{2}$. At this short exposure to $\mathrm{NO}_{3}$ we do not expect significant oxidation of the methylene groups in UDT. As peak intensities depend on the orientation of the different vibrational modes [Ulman, 1991], we assume that the negative peaks appearing in the region of $3000-2800 \mathrm{~cm}^{-1}$ are due to increased disorder within the monolayer due to reaction of the double bond. This is consistent with results by Moise and Rudich [2001] who observed almost complete disappearance of the $\mathrm{CH}_{2}$ stretching peaks in IR, while XPS indicated only a $20 \%$ reduction in total carbon and a significant fraction of remaining unoxidized $\mathrm{C}(1 \mathrm{~s})$. The IR spectra clearly showed the formation of a peak at $1281 \mathrm{~cm}^{-1}$. On the basis of Table 1, this could be due to an organonitrate, organoperoxynitrate, or peroxyacylnitrate. It seems unlikely that the identified surface species are organoperoxynitrates or peroxyacylnitrates, since these species typically have a short lifetime and are expected to decompose while the substrates are transferred to the IR spectrometer for analysis, as discussed above. We can conclude that nitrogen species are formed, contrary to the conclusion one may reach from the XPS data.

\subsubsection{ToF-SIMS Measurements}

[51] Shown in Figure 9 are negative ion ToF-SIMS spectra for UDT before (Figure 9a) and after exposure to $\mathrm{NO}_{3}$ (Figure 9b). As with ODT, spectra before $\mathrm{NO}_{3}$ exposure showed $\mathrm{Au}_{\mathrm{x}} \mathrm{S}_{\mathrm{y}}$ clusters, low molecular weight fragments of the monolayer chains $\left(\mathrm{C}^{-}, \mathrm{CH}^{-}, \mathrm{C}_{2} \mathrm{H}^{-}, \mathrm{S}^{-}, \mathrm{SH}^{-}\right)$, and characteristic peaks for the whole UDT molecule. These peaks are labeled $\mathrm{M}$, which indicates $\mathrm{C}_{11} \mathrm{H}_{21}$. All peaks characteristic of the unoxidized hydrocarbon SAMs decreased or disappeared upon $\mathrm{NO}_{3}$ exposure $\left(\mathrm{C}^{-}, \mathrm{CH}^{-}\right.$, $\mathrm{C}_{2} \mathrm{H}^{-}, \mathrm{S}^{-}, \mathrm{SH}^{-}, \mathrm{MS}^{-}$, and $\left.\mathrm{Au}(\mathrm{MS})_{2}^{-}\right)$. New peaks of high intensities formed especially in the $\mathrm{m} / \mathrm{z}$ region $<100$, which could be attributed to $\mathrm{O}^{-}, \mathrm{OH}^{-}, \mathrm{NO}_{2}^{-}, \mathrm{NO}_{3}^{-}, \mathrm{SO}_{3}^{-}$, and $\mathrm{HSO}_{4}^{-}$. As with ODT, peaks for $\mathrm{NO}_{2}^{-}$and $\mathrm{NO}_{3}^{-}$led us to conclude that nitrogen containing functional groups formed during the oxidization of UDT by $\mathrm{NO}_{3}$, but decomposed during XPS measurements.

[52] Again, as with ODT, $\mathrm{NO}_{3}$ exposed UDT SAMs showed peaks of $\mathrm{SO}_{3}^{-}$and $\mathrm{SO}_{4}^{-}$. This is consistent with the appearance of a $S(2 p)$ peak of oxidized sulfur in XPS spectra of UDT exposed to $\geq 9.1 \times 10^{-6} \mathrm{~atm} \mathrm{sec}$.

\subsubsection{Contact Angle Measurements}

[53] The initial contact angle determined before $\mathrm{NO}_{3}$ exposure was $92^{\circ} \pm 5^{\circ}$ for UDT (number given here is the average value and standard deviation). Literature values for monolayers of terminal alkenes $\left(\mathrm{C}_{8}-\mathrm{C}_{19}\right)$ were reported at $89^{\circ}-107^{\circ}$ [Bain et al., 1989; Bertram et al., 2001; Dubowski et al., 2004; Robinson et al., 1995; Rudich et al., 2000; Thomas et al., 2001; Wasserman et al., 1989]. The large contact angles observed for the unoxidized monolayers indicate the presence of well-ordered SAMs in this study. $\mathrm{NO}_{3}$ exposure of UDT samples was $9.06 \times 10^{-5} \mathrm{~atm} \mathrm{sec}$ (equivalent to $50 \mathrm{ppt} \mathrm{NO}_{3}$ for 3 weeks). After this exposure, the contact angle on UDT had decreased to $59^{\circ} \pm 6^{\circ}$, a decrease of $33^{\circ}$. This gives further support that the monolayers were oxidized leading to a more hydrophilic surface. Previous studies investigating changes in $\mathrm{H}_{2} \mathrm{O}$ contact angles on hydrocarbon monolayers $\left(\mathrm{C}_{8}-\mathrm{C}_{19}\right)$ after exposure to gasphase reactants reported the following data for terminal alkene monolayers: after $\mathrm{F}$ radical exposure $\theta=75^{\circ}$ [Robinson et al., 1995], and after $\mathrm{O}_{3}$ exposure $\theta=74^{\circ}$ and $\sim 70^{\circ}$ [Dubowski et al., 2004; Thomas et al., 2001].

\subsubsection{Proposed Reaction Mechanism}

[54] Shown in Figure 10 is the proposed mechanism for oxidation of an alkene monolayer by $\mathrm{NO}_{3}$ radicals in the presence of $\mathrm{O}_{2}$ and $\mathrm{NO}_{2}$ based on gas-phase chemistry [Atkinson, 1991; Atkinson, 1997, 2000; Berndt and Böge, 1995; Gong et al., 2005; Kwok et al., 1996; Noda et al., 2000; Tuazon et al., 1999]. The gas-phase reaction of $\mathrm{NO}_{3}$ with alkenes is assumed to proceed via addition of $\mathrm{NO}_{3}$ to the $\mathrm{C}-\mathrm{C}$ double bond (Figure 10, step 1). This leads to a $\mathrm{C}-\mathrm{ONO}_{2}$ functional group on one of the two $\mathrm{C}$ atoms of the double bond and leaves an alkyl radical at the other $\mathrm{C}$ atom. 



Figure 9. Negative ion ToF-SIMS spectra of UDT on gold in the $\mathrm{m} / \mathrm{z} 1-600$ region. (a) Spectrum was obtained on a UDT sample without $\mathrm{NO}_{3}$ exposure. (b) Spectrum was obtained after an $\mathrm{NO}_{3}$ exposure of $9.1 \times 10^{-6}$ atm s (equivalent to $50 \mathrm{ppt}$ for $50 \mathrm{~h}$ ).

This radical compound is expected to react further with $\mathrm{O}_{2}$ to an alkylperoxy radical $\left(\mathrm{RO}_{2}\right.$, step 2) [Finlayson-Pitts and Pitts, 2000].

[55] Reactions of the $\mathrm{RO}_{2}$ radical are believed to occur in the same way as those of the $\mathrm{RO}_{2}$ in the alkane reaction scheme (Figure 4), except that the neighboring $\mathrm{C}$ atom contains an $\mathrm{ONO}_{2}$ functional group. An additional difference is the fact that the scission channel leads to the elimination of $\mathrm{NO}_{2}$ and the formation of two aldehydes (step 9).

[56] Not shown in Figure 10 are additional reactions that the alkyl nitrate radical may undergo at low pressures in competition with step 2 . When the nitrate radical adds to the double bond, an excited state results. If this excited state is not collisionally stabilized, it can decompose to $\mathrm{NO}_{2}$ and an aldehyde or ketone or alternatively eliminate $\mathrm{NO}_{2}$ and form an epoxide that reacts further to a carbonyl [Atkinson, 1991; Dlugokencky and Howard, 1989]. The importance of these steps on a surface however is unclear.

[57] As a reminder, the XPS results are consistent with the formation of $\mathrm{C}-\mathrm{O}, \mathrm{C}=\mathrm{O}$, and $\mathrm{C}(=\mathrm{O}) \mathrm{O}$ functional groups. IR and ToF-SIMS analysis showed the formation of nitrogencontaining species, likely organonitrates. Scission of the carbon chain at the double bond could not be confirmed, but could not be ruled out either. The formation of C-O and $\mathrm{C}=\mathrm{O}$ functional groups could be explained by step 4 , the
Russell mechanism. Formation of C-O could also be explained by step 7, and the formation of $\mathrm{C}=\mathrm{O}$ could also be explained by steps 8 and 9 . Carboxylic functional groups determined using XPS were probably formed in secondary reactions, for example, oxidation of aldehydes [George et al., 2007].

[58] Our experiments are the first to investigate heterogeneous reactions between radicals and alkene monolayers in the presence of $\mathrm{O}_{2}$ and $\mathrm{NO}_{2}$, so our product analysis should be helpful for understanding this heterogeneous mechanism. D'Andrea et al. [2008] investigated the reaction between $\mathrm{OH}$ and an alkene monolayer, but in the absence of $\mathrm{NO}_{2}$ and $\mathrm{O}_{2}$, so the results are not directly comparable. In addition, both Hung et al. [2005] and Docherty and Ziemann [2006] studied the reaction between $\mathrm{NO}_{3}$ (in the presence of $\mathrm{O}_{2}$ and $\mathrm{NO}_{2}$ ) and liquid alkene particles. Hung et al. [2005] observed organonitrate, peroxynitrate, organonitrite, and carbonyl functional groups using infrared spectroscopy and high molecular weight products were also observed using LC-MS. Docherty and Ziemann [2006], using mass spectrometry, identified hydroxyl nitrates, carbonyl nitrates, dinitrates, hydroxydinitrates, and possibly more highly nitrated products. It is interesting to note that several of the functional groups identified in these previous liquid reactions were also identified in our current monolayer studies. It therefore appears 


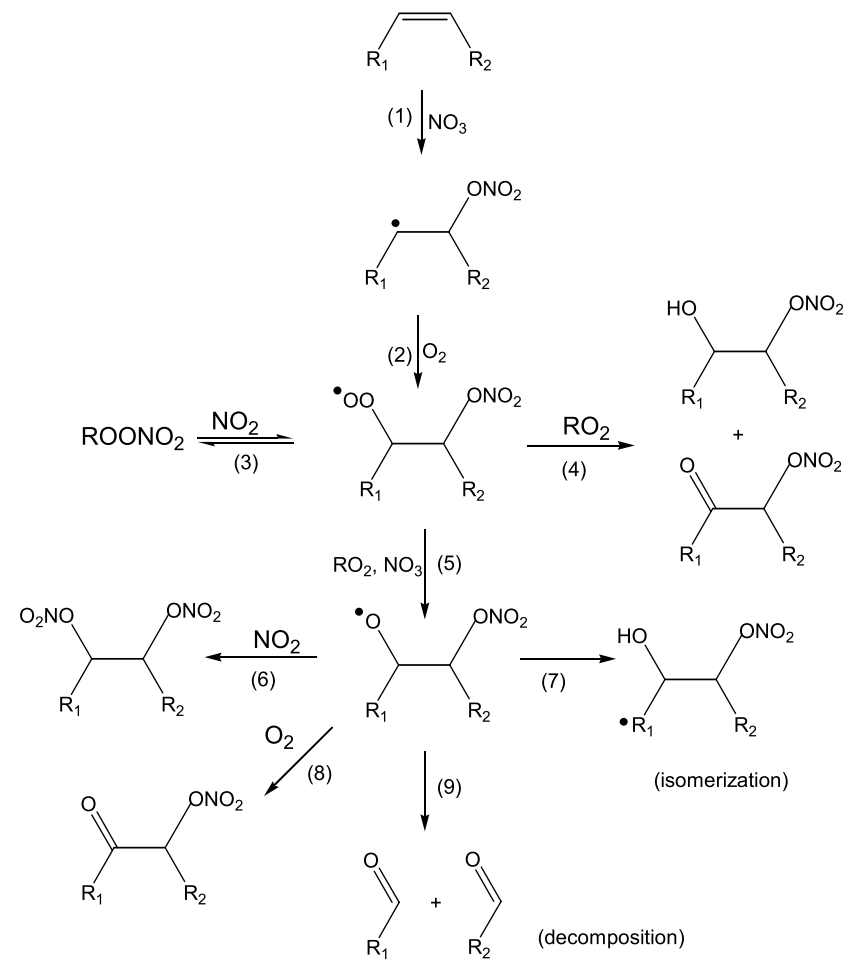

Figure 10. Proposed reaction mechanism for an alkene surface with $\mathrm{NO}_{3}$ in the presence of $\mathrm{NO}_{2}$ and $\mathrm{O}_{2}$ based on gas-phase chemistry.

that the reaction pathways for the alkene monolayers are similar to the reaction pathways for the liquid, although the relative importance of the different channels may differ.

[59] Also, when studying the reaction between $\mathrm{NO}_{3}$ and liquid alkene particles, Docherty and Ziemann [2006] observed substantial organonitrate formation after the double bond was completely reacted, which was attributed to either the reaction of $\mathrm{N}_{2} \mathrm{O}_{5}$ with a hydroxyl group or $\mathrm{H}$-atom abstraction. This latter explanation is consistent with the alkane monolayer results we presented above.

\section{Conclusions and Atmospheric Implications}

[60] For the alkane SAM, IR spectroscopy and ToF-SIMS confirmed the formation of organonitrates $\left(\mathrm{RONO}_{2}\right)$. The observation of organonitrates is in contrast to the XPS data by Knopf et al. [2006], which showed very little N(1s) signal. The formation of organonitrates in our experiment may explain why we did not see significant decomposition of the carbon chains in our recent studies with $\mathrm{NO}_{3}$ radicals. Formation of organonitrates removes alkyl peroxy $\left(\mathrm{RO}_{2}\right)$ and/or alkoxy (RO) species from the system, and hence will reduce the importance of the decomposition channel. Possibly this is one of the differences between our work with $\mathrm{NO}_{3}$ and alkane monolayers and some of the recent studies with $\mathrm{OH}$ and alkane SAMs where significant decomposition was observed. In the case of alkene SAMs, the $\gamma$ value of the terminal alkene UDT obtained in this study is higher than the values obtained by Moise et al. [2002] using liquid and solid alkene bulk films. A possible reason for this difference may be the location of the double bond at the interface. Using the $\gamma$ value determined in our studies, we show that oxidation of an alkene monolayer by $\mathrm{NO}_{3}$ can be significantly more important than oxidation by $\mathrm{OH}, \mathrm{Cl}$, and $\mathrm{Br}$ in the atmosphere. Only $\mathrm{O}_{3}$ is of equal importance to $\mathrm{NO}_{3}$ owing to its much higher tropospheric concentration. We also used our $\gamma$ value for the alkene SAM to show that the lifetime of an alkene monolayer in the atmosphere will be short (approximately $23 \mathrm{~min}$ ) assuming an $\mathrm{NO}_{3}$ concentration of $50 \mathrm{ppt}$.

[61] XPS, IR and ToF-SIMS were used to identify surface functional groups after the oxidation of the alkene monolayers by $\mathrm{NO}_{3}$. The results are consistent with the formation of $\mathrm{C}-\mathrm{O}$, aldehyde/ketone, carboxylic groups, and nitrogen species. It is interesting to note that several of the functional groups identified in previous studies of $\mathrm{NO}_{3}$ radicals (in the presence of $\mathrm{O}_{2}$ and $\mathrm{NO}_{2}$ ) with liquid alkene films were also identified in our current monolayer studies.

[62] Acknowledgments. The authors would like to acknowledge the help of D. A. Knopf and J. Mak in the early stages of $\mathrm{NO}_{3}$ and monolayer experiments. K. C. Wong is acknowledged for XPS measurements, D. Bizzotto for assistance with IR, M. J. Wheeler for help with contact angle images. A portion of this research (ToF-SIMS measurements) was performed using EMSL, a national scientific user facility sponsored by the Department of Energy's Office of Biological and Environmental Research located at Pacific Northwest National Laboratory. The authors thank Z. Zhu for performing the ToF-SIMS analysis. The authors are very grateful to L. Fiegland and T. Morris at Virginia Tech, Blacksburg, Virginia, for synthesizing and providing undecenethiol. This work was funded by the Natural Science and Engineering Research Council, the Canada Foundation for Innovation, and the Canada Research Chair Program.

\section{References}

Aldener, M., et al. (2006), Reactivity and loss mechanisms of $\mathrm{NO}_{3}$ and $\mathrm{N}_{2} \mathrm{O}_{5}$ in a polluted marine environment: Results from in situ measurements during New England Air Quality Study 2002, J. Geophys. Res., 111, D23S73, doi:10.1029/2006JD007252.

Allen, D. T., E. J. Palen, M. I. Haimov, S. V. Hering, and J. R. Young (1994), Fourier transform infrared spectroscopy of aerosol collected in a low-pressure impactor (Lpi/Ftir): Method development and field calibration, Aerosol Sci. Technol., 21(4), 325-342, doi:10.1080/02786829408959719.

Allen, G., J. J. Remedios, and K. M. Smith (2005), Low temperature midinfrared cross-sections for peroxyacetyl nitrate (PAN) vapour, Atmos. Chem. Phys., 5, 3153-3158.

Alvarado, A., E. C. Tuazon, S. M. Aschmann, J. Arey, and R. Atkinson (1999), Products and mechanisms of the gas-phase reactions of OH radicals and $\mathrm{O}_{3}$ with 2-methyl-3-buten-2-ol, Atmos. Environ., 33(18), $2893-$ 2905, doi:10.1016/S1352-2310(99)00106-5.

Arens, F., L. Gutzwiller, H. W. Gäggeler, and M. Ammann (2002), The reaction of $\mathrm{NO}_{2}$ with solid anthrarobin (1,2,10-trihydroxy-anthracene), Phys. Chem. Chem. Phys., 4(15), 3684-3690, doi:10.1039/b201713j.

Atkinson, R. (1991), Kinetics and mechanisms of the gas-phase reactions of the $\mathrm{NO}_{3}$ radical with organic compounds, J. Phys. Chem. Ref. Data, 20(3), 459-507.

Atkinson, R. (1997), Gas-phase tropospheric chemistry of volatile organic compounds. 1. Alkanes and alkenes, J. Phys. Chem. Ref. Data, 26(2), $215-290$.

Atkinson, R. (2000), Atmospheric chemistry of VOCs and $\mathrm{NO}_{\mathrm{x}}$, Atmos Environ., 34(12-14), 2063-2101, doi:10.1016/S1352-2310(99)00460-4. Atkinson, R., A. M. Winer, and J. N. Pitts (1986), Estimation of nighttime $\mathrm{N}_{2} \mathrm{O}_{5}$ concentrations from ambient $\mathrm{NO}_{2}$ and $\mathrm{NO}_{3}$ radical concentrations and the role of $\mathrm{N}_{2} \mathrm{O}_{5}$ in nighttime chemistry, Atmos. Environ., 20(2), 331-339, doi:10.1016/0004-6981(86)90035-1.

Atkinson, R., E. C. Tuazon, and S. M. Aschmann (1998), Products of the gas-phase reaction of the $\mathrm{OH}$ radical with 3-methyl-1-butene in the presence of NO, Int. J. Chem. Kinet., 30(8), 577-587, doi:10.1002/ (SICI)1097-4601(1998)30:8<577::AID-KIN7>3.0.CO;2-P.

Bain, C. D., E. B. Troughton, Y. T. Tao, J. Evall, G. M. Whitesides, and R. G. Nuzzo (1989), Formation of monolayer films by the spontaneous assembly of organic thiols from solution onto gold, J. Am. Chem. Soc., 111, 321-335, doi:10.1021/ja00183a049.

Berndt, T., and O. Böge (1995), Products and mechanism of the reaction of $\mathrm{NO}_{3}$ with selected acyclic monoalkenes, J. Atmos. Chem., 21(3), 275-291, doi:10.1007/BF00696759.

Bertram, A. K., A. V. Ivanov, M. Hunter, L. T. Molina, and M. J. Molina (2001), The reaction probability of $\mathrm{OH}$ on organic surfaces of tropospheric interest, J. Phys. Chem. A, 105(41), 9415-9421, doi:10.1021/jp0114034. 
Briggs, D., and G. Beamson (1992), Primary and secondary oxygen-induced $\mathrm{C} 1 \mathrm{~s}$ binding energy shifts in X-ray photoelectron spectroscopy of polymers, Anal. Chem., 64(15), 1729-1736, doi:10.1021/ac00039a018.

Bröske, R., J. Kleffmann, and P. Wiesen (2003), Heterogeneous conversion of $\mathrm{NO}_{2}$ on secondary organic aerosol surfaces: A possible source of nitrous acid (HONO) in the atmosphere?, Atmos. Chem. Phys., 3, 469-474.

Cassanelli, P., R. A. Cox, J. J. Orlando, and G. S. Tyndall (2006), An FT-IR study of the isomerization of 1-butoxy radicals under atmospheric conditions, J. Photochem. Photobiol. A, 177(2-3), 109-115, doi:10.1016/ j.jphotochem.2005.11.001.

D’Andrea, T. M., X. Zhang, E. B. Jochnowitz, T. G. Lindeman, C. J. S. M. Simpson, D. E. David, T. J. Curtiss, J. R. Morris, and G. B. Ellison (2008), Oxidation of organic films by beams of hydroxyl radicals, J. Phys. Chem. B, 112(2), 535-544, doi:10.1021/jp7096108.

Diamond, M. L., S. E. Gingrich, K. Fertuck, B. E. McCarry, G. A. Stern, B. Billeck, B. Grift, D. Brooker, and T. D. Yager (2000), Evidence for organic film on an impervious urban surface: Characterization and potential teratogenic effects, Environ. Sci. Technol., 34(14), 2900-2908, doi:10.1021/es9906406.

Dicke, C., M. Morstein, and G. Hahner (2002), Surface inorganic chemistry: The reaction of hydroxyl-terminated thiols on gold with a zirconium coordination compound, Langmuir, 18(2), 336-344, doi:10.1021/ la010854c.

Dlugokencky, E. J., and C. J. Howard (1989), Studies of $\mathrm{NO}_{3}$ radical reactions with some atmospheric organic compounds at low pressures, J. Phys. Chem., 93(3), 1091-1096.

Docherty, K. S., and P. J. Ziemann (2006), Reaction of oleic acid particles with $\mathrm{NO}_{3}$ radicals: Products, mechanism, and implications for radicalinitiated organic aerosol oxidation, J. Phys. Chem. A, 110(10), 35673577, doi:10.1021/jp0582383.

Donaldson, D. J., B. T. Mmereki, S. R. Chaudhuri, S. Handley, and M. Oh (2005), Uptake and reaction of atmospheric organic vapours on organic films, Faraday Discuss., 130, 227-239, doi:10.1039/b418859d.

Dubowski, Y., J. Vieceli, D. J. Tobias, A. Gomez, A. Lin, S. A. Nizkorodov, T. M. McIntire, and B. J. Finlayson-Pitts (2004), Interaction of gas-phase ozone at $296 \mathrm{~K}$ with unsaturated self-assembled monolayers: A new look at an old system, J. Phys. Chem. A, 108(47), 10,473-10,485, doi:10.1021/jp046604x.

Ebbing, D. D. (1993), General Chemistry, Houghton Mifflin, Boston, Mass.

Eliason, T. L., J. B. Gilman, and V. Vaida (2004), Oxidation of organic films relevant to atmospheric aerosols, Atmos. Environ., 38(9), $1367-$ 1378, doi:10.1016/j.atmosenv.2003.11.025.

Ellison, G. B., A. F. Tuck, and V. Vaida (1999), Atmospheric processing of organic aerosols, J. Geophys. Res., 104(D9), 11,633-11,641.

Esteve, W., H. Budzinski, and E. Villenave (2003), Heterogeneous reactivity of $\mathrm{OH}$ radicals with phenanthrene, Polycyclic Aromat. Compounds, 23(5), 441-456, doi:10.1080/714040938.

Esteve, W., H. Budzinski, and E. Villenave (2004), Relative rate constants for the heterogeneous reactions of $\mathrm{OH}, \mathrm{NO}_{2}$ and $\mathrm{NO}$ radicals with polycyclic aromatic hydrocarbons adsorbed on carbonaceous particles. Part 1 : PAHs adsorbed on $1-2 \mu \mathrm{m}$ calibrated graphite particles, Atmos. Environ. 38(35), 6063-6072, doi:10.1016/j.atmosenv.2004.05.059.

Esteve, W., H. Budzinski, and E. Villenave (2006), Relative rate constants for the heterogeneous reactions of $\mathrm{NO}_{2}$ and $\mathrm{OH}$ radicals with polycyclic aromatic hydrocarbons adsorbed on carbonaceous particles. Part 2: PAHs adsorbed on diesel particulate exhaust SRM 1650a, Atmos. Environ., 40(2), 201-211, doi:10.1016/j.atmosenv.2005.07.053.

Finlayson-Pitts, B. J., and J. N. Pitts (2000), Chemistry of the Upper and Lower Atmosphere, Academic Press, San Diego, Calif.

George, I. J., A. Vlasenko, J. G. Slowik, K. Broekhuizen, and J. P. D. Abbatt (2007), Heterogeneous oxidation of saturated organic aerosols by hydroxyl radicals: Uptake kinetics, condensed-phase products, and particle size change, Atmos. Chem. Phys., 7(16), 4187-4201.

Geyer, A., B. Alicke, S. Konrad, T. Schmitz, J. Stutz, and U. Platt (2001), Chemistry and oxidation capacity of the nitrate radical in the continental boundary layer near Berlin, J. Geophys. Res., 106(D8), 8013-8025, doi:10.1029/2000JD900681.

Gill, P. S., T. E. Graedel, and C. J. Weschler (1983), Organic films on atmospheric aerosol-particles, fog droplets, cloud droplets, raindrops, and snowflakes, Rev. Geophys., 21(4), 903-920, doi:10.1029/ RG021i004p00903.

Gong, H. M., A. Matsunaga, and P. J. Ziemann (2005), Products and mechanism of secondary organic aerosol formation from reactions of linear alkenes with $\mathrm{NO}_{3}$ radicals, J. Phys. Chem. A, 109(19), 43124324, doi:10.1021/jp0580241.

Gross, S., and A. K. Bertram (2008), Reactive uptake of $\mathrm{NO}_{3}, \mathrm{~N}_{2} \mathrm{O}_{5}, \mathrm{NO}_{2}$, $\mathrm{HNO}_{3}$, and $\mathrm{O}_{3}$ on three types of polycyclic aromatic hydrocarbon surfaces, J. Phys. Chem. A, 112(14), 3104-3113, doi:10.1021/jp7107544.

Hallquist, M., I. Wangberg, E. Ljungstrom, I. Barnes, and K. H. Becker (1999), Aerosol and product yields from $\mathrm{NO}_{3}$ radical-initiated oxidation of selected monoterpenes, Environ. Sci. Technol., 33(4), 553-559, doi:10.1021/es980292s.

Hearn, J. D., and G. D. Smith (2006), A mixed-phase relative rates technique for measuring aerosol reaction kinetics, Geophys. Res. Lett., 33, L17805, doi:10.1029/2006GL026963.

Hearn, J. D., L. H. Renbaum, X. Wang, and G. D. Smith (2007), Kinetics and products from reaction of $\mathrm{Cl}$ radicals with dioctyl sebacate (DOS) particles in $\mathrm{O}_{2}$ : A model for radical-initiated oxidation of organic aerosols, Phys. Chem. Chem. Phys., 9(34), 4803-4813, doi:10.1039/b707523e.

Hung, H. M., Y. Katrib, and S. T. Martin (2005), Products and mechanisms of the reaction of oleic acid with ozone and nitrate radical, J. Phys. Chem. $A, 109(20), 4517-4530$, doi:10.1021/jp0500900.

Inazu, K., T. Kobayashi, and Y. Hisamatsu (1997), Formation of 2-nitrofluoranthene in gas-solid heterogeneous photoreaction of fluoranthene supported on oxide particles in the presence of nitrogen dioxide, Chemosphere, 35(3), 607-622, doi:10.1016/S0045-6535(97)00124-0.

Inman, C. E., S. M. Reed, and J. E. Hutchison (2004), In situ deprotection and assembly of S-tritylalkanethiols on gold yields monolayers comparable to those prepared directly from alkanethiols, Langmuir, 20(21), 9144-9150, doi:10.1021/la049627b.

Ishida, T., S. Tsuneda, N. Nishida, M. Hara, H. Sasabe, and W. Knoll (1997), Surface-conditioning effect of gold substrates on octadecanethiol self-assembled monolayer growth, Langmuir, 13(17), 4638-4643, doi:10.1021/la970241t.

Ishii, S., Y. Hisamatsu, K. Inazu, T. Kobayashi, and K. Aika (2000), Mutagenic nitrated benzo[a]pyrene derivatives in the reaction product of benzo[a]pyrene in $\mathrm{NO}_{2}$-air in the presence of $\mathrm{O}_{3}$ or under photoirradiation, Chemosphere, 41(11), 1809-1819, doi:10.1016/S0045-6535(00)00029-1.

Jang, M. S., and R. M. Kamens (2001), Characterization of secondary aerosol from the photooxidation of toluene in the presence of $\mathrm{NO}_{\mathrm{x}}$ and 1-propene, Environ. Sci. Technol., 35(18), 3626-3639, doi:10.1021/es010676+.

Kahan, T. F., N. O. A. Kwamena, and D. J. Donaldson (2006), Heterogeneous ozonation kinetics of polycyclic aromatic hydrocarbons on organic films, Atmos. Environ., 40(19), 3448-3459, doi:10.1016/j.atmosenv. 2006.02 .004

Kanakidou, M., et al. (2005), Organic aerosol and global climate modelling: A review, Atmos. Chem. Phys., 5, 1053-1123.

Karagulian, F., and M. J. Rossi (2007), Heterogeneous chemistry of the $\mathrm{NO}_{3}$ free radical and $\mathrm{N}_{2} \mathrm{O}_{5}$ on decane flame soot at ambient temperature: Reaction products and kinetics, J. Phys. Chem. A, 111(10), 1914-1926, doi:10.1021/jp0670891.

Karagulian, F., C. W. Dilbeck, and B. J. Finlayson-Pitts (2008), Unusual oxidation of organics from the bottom up and atmospheric implications, J. Am. Chem. Soc., 130, 11,272-11,273, doi:10.1021/ja8041965.

Knopf, D. A., L. M. Anthony, and A. K. Bertram (2005), Reactive uptake of $\mathrm{O}_{3}$ by multicomponent and multiphase mixtures containing oleic acid, J. Phys. Chem. A, 109(25), 5579-5589, doi:10.1021/jp0512513.

Knopf, D. A., J. Mak, S. Gross, and A. K. Bertram (2006), Does atmospheric processing of saturated hydrocarbon surfaces by $\mathrm{NO}_{3}$ lead to volatilization?, Geophys. Res. Lett., 33, L17816, doi:10.1029/ 2006GL026884

Kwan, A. J., et al. (2006), On the flux of oxygenated volatile organic compounds from organic aerosol oxidation, Geophys. Res. Lett., 33, L15815, doi:10.1029/2006GL026144.

Kwok, E. S. C., S. M. Aschmann, J. Arey, and R. Atkinson (1996), Product formation from the reaction of the $\mathrm{NO}_{3}$ radical with isoprene and rate constants for the reactions of methacrolein and methyl vinyl ketone with the $\mathrm{NO}_{3}$ radical, Int. J. Chem. Kinet., 28(12), 925-934.

Lai, C. C., and B. J. Finlayson-Pitts (1991), Reactions of dinitrogen pentoxide and nitrogen dioxide with 1-palmitoyl-2-oleoyl-Sn-glycero-3-phosphocholine, Lipids, 26(4), 306-314, doi:10.1007/BF02537142.

Laibinis, P. E., R. L. Graham, H. A. Biebuyck, and G. M. Whitesides (1991), X-ray-damage to $\mathrm{CF}_{3} \mathrm{CO}_{2}$-terminated organic monolayers on Si/Au: Principal effect of electrons, Science, 254(5034), 981-983, doi:10.1126/science.254.5034.981.

Lambe, A. T., J. Y. Zhang, A. M. Sage, and N. M. Donahue (2007), Controlled $\mathrm{OH}$ radical production via ozone-alkene reactions for use in aerosol aging studies, Environ. Sci. Technol., 41(7), 2357-2363, doi:10.1021/es061878e.

Mak, J., S. Gross, and A. K. Bertram (2007), Uptake of $\mathrm{NO}_{3}$ on soot and pyrene surfaces, Geophys. Res. Lett., 34, L10804, doi:10.1029/ 2007GL029756.

McNeill, V. F., G. M. Wolfe, and J. A. Thornton (2007), The oxidation of oleate in submicron aqueous salt aerosols: Evidence of a surface process, J. Phys. Chem. A, 111(6), 1073-1083, doi:10.1021/jp066233f

McNeill, V. F., R. L. N. Yatavelli, J. A. Thornton, C. B. Stipe, and O. Landgrebe (2008), The heterogeneous $\mathrm{OH}$ oxidation of palmitic acid in single component and internally mixed aerosol particles: Vaporization, secondary chemistry, and the role of particle phase, Atmos. Chem. Phys., $8(17), 5465-5478$ 
Moise, T., and Y. Rudich (2000), Reactive uptake of ozone by proxies for organic aerosols: Surface versus bulk processes, J. Geophys. Res. 105(D11), 14,667-14,676.

Moise, T., and Y. Rudich (2001), Uptake of $\mathrm{Cl}$ and $\mathrm{Br}$ by organic surfaces: A perspective on organic aerosols processing by tropospheric oxidants, Geophys. Res. Lett., 28(21), 4083-4086, doi:10.1029/2001GL013583.

Moise, T., R. K. Talukdar, G. J. Frost, R. W. Fox, and Y. Rudich (2002), Reactive uptake of $\mathrm{NO}_{3}$ by liquid and frozen organics, J. Geophys. Res., 107(D2), 4014, doi:10.1029/2001JD000334.

Molina, M. J., A. V. Ivanov, S. Trakhtenberg, and L. T. Molina (2004), Atmospheric evolution of organic aerosol, Geophys. Res. Lett., 31, L22104, doi:10.1029/2004GL020910.

Noda, J., M. Hallquist, S. Langer, and E. Ljungstrom (2000), Products from the gas-phase reaction of some unsaturated alcohols with nitrate radicals, Phys. Chem. Chem. Phys., 2(11), 2555-2564, doi:10.1039/b000251h.

Offord, D. A., C. M. John, M. R. Linford, and J. H. Griffin (1994), Contact angle goniometry, ellipsometry, and time-of-flight secondary ion mass spectrometry of gold supported, mixed self-assembled monolayers formed from alkyl mercaptans, Langmuir, 10(3), 883-889, doi:10.1021/ la00015a045.

Owens, T. M., B. J. Ludwig, K. S. Schneider, D. R. Fosnacht, B. G. Orr, and M. M. B. Holl (2004), Oxidation of alkylsilane-based monolayers on gold, Langmuir, 20(22), 9636-9645, doi:10.1021/la0496385.

Palen, E. J., D. T. Allen, S. N. Pandis, S. E. Paulson, J. H. Seinfeld, and R. C. Flagan (1992), Fourier transform infrared analysis of aerosol formed in the photooxidation of isoprene and beta-pinene, Atmos. Environ. Part A, 26(7), 1239-1251.

Paz, Y., S. Trakhtenberg, and R. Naaman (1992), Destruction of organized organic monolayers by oxygen atoms, J. Phys. Chem., 96(26), 10,964$10,967$.

Peanasky, J. S., and R. L. McCarley (1998), Surface-confined monomers on electrode surfaces. 4. Electrochemical and spectroscopic characterization of undec-10-ene-1-thiol self-assembled monolayers on Au, Langmuir, 14(1), 113-123, doi:10.1021/la970823a.

Perraudin, E., H. Budzinski, and E. Villenave (2005), Kinetic study of the reactions of $\mathrm{NO}_{2}$ with polycyclic aromatic hydrocarbons adsorbed on silica particles, Atmos. Environ., 39(35), 6557-6567, doi:10.1016/j.atmosenv. 2005.07.037.

Platt, U., D. Perner, A. M. Winer, G. W. Harris, and J. N. Pitts (1980), Detection of $\mathrm{NO}_{3}$ in the polluted troposphere by differential optical absorption, Geophys. Res. Lett., 7(1), 89-92, doi:10.1029/GL007i001p00089.

Pruppacher, H. R., and J. D. Klett (1997), Microphysics of Clouds and Precipitation, Kluwer Acad., Dordrecht, Netherlands.

Robinson, A. L., N. M. Donahue, and W. F. Rogge (2006), Photochemical oxidation and changes in molecular composition of organic aerosol in the regional context, J. Geophys. Res., 111, D03302, doi:10.1029/ 2005JD006265.

Robinson, G. N., A. Freedman, and R. L. Graham (1995), Reactions of fluorine atoms with self-assembled monolayers of alkanethiolates, Langmuir, 11(7), 2600-2608, doi:10.1021/la00007a045.

Rudich, Y. (2003), Laboratory perspectives on the chemical transformations of organic matter in atmospheric particles, Chem. Rev., 103(12), 50975124, doi:10.1021/cr020508f.

Rudich, Y., I. Benjamin, R. Naaman, E. Thomas, S. Trakhtenberg, and R. Ussyshkin (2000), Wetting of hydrophobic organic surfaces and its implications to organic aerosols in the atmosphere, J. Phys. Chem. A, 104(22), 5238-5245, doi:10.1021/jp994203p.

Rudich, Y., N. M. Donahue, and T. F. Mentel (2007), Aging of organic aerosol: Bridging the gap between laboratory and field studies, Annu. Rev. Phys. Chem., 58,321-352, doi:10.1146/annurev.physchem. 58.032806 .104432$.

Schott, G., and N. Davidson (1958), Shock waves in chemical kinetics: The decomposition of $\mathrm{N}_{2} \mathrm{O}_{5}$ at high temperatures, J. Am. Chem. Soc., 80, 1841-1853, doi:10.1021/ja01541a019.
Seinfeld, J. H., and S. N. Pandis (2006), Atmospheric Chemistry and Physics: From Air Pollution to Climate Change, John Wiley, Hoboken, N. J.

Simpson, A. J., B. Lam, M. L. Diamond, D. J. Donaldson, B. A. Lefebvre, A. Q. Moser, A. J. Williams, N. I. Larin, and M. P. Kvasha (2006), Assessing the organic composition of urban surface films using nuclear magnetic resonance spectroscopy, Chemosphere, 63(1), 142-152, doi:10.1016/j.chemosphere.2005.07.013.

Sohn, S., M. Schröder, D. Lipinsky, and H. F. Arlinghaus (2004), ToF-SIMS investigations of the degeneration processes of self-assembled monolayers of alkanethiols on gold, Surf. Interface Anal., 36(8), 1222-1226, doi:10.1002/sia.1881.

Stutz, J., B. Alicke, R. Ackermann, A. Geyer, A. White, and E. Williams (2004), Vertical profiles of $\mathrm{NO}_{3}, \mathrm{~N}_{2} \mathrm{O}_{5}, \mathrm{O}_{3}$, and $\mathrm{NO}_{\mathrm{x}}$ in the nocturnal boundary layer: 1. Observations during the Texas Air Quality Study 2000, J. Geophys. Res., 109, D12306, doi:10.1029/2003JD004209.

Sun, L. M., and J. A. Gardella (2002), Oxidation-assisted secondary ion mass spectrometry methodology to quantify mixed alkylthiol self-assembled monolayers on gold: Applications to competitive chemical adsorption, Langmuir, 18(24), 9289-9295, doi:10.1021/la011655w.

Thomas, E. R., G. J. Frost, and Y. Rudich (2001), Reactive uptake of ozone by proxies for organic aerosols: Surface-bound and gas-phase products, J. Geophys. Res., 106(D3), 3045-3056.

Tuazon, E. C., A. Alvarado, S. M. Aschmann, R. Atkinson, and J. Arey (1999), Products of the gas-phase reactions of 1,3-butadiene with OH and $\mathrm{NO}_{3}$ radicals, Environ. Sci. Technol., 33(20), 3586-3595, doi:10.1021/ es990193u.

Ulman, A. (1991), An Introduction to Ultrathin Organic Films From LangmuirBlodgett to Self-Assembly, Academic Press, San Diego, Calif.

Ulman, A. (1995), Characterization of Organic Thin Films, ButterworthHeinemann, Boston, Mass.

Usher, C. R., A. E. Michel, and V. H. Grassian (2003a), Reactions on mineral dust, Chem. Rev., 103(12), 4883-4939, doi:10.1021/cr020657y.

Usher, C. R., A. E. Michel, D. Stec, and V. H. Grassian (2003b), Laboratory studies of ozone uptake on processed mineral dust, Atmos. Environ., 37(38), 5337-5347, doi:10.1016/j.atmosenv.2003.09.014.

Vieceli, J., O. L. Ma, and D. J. Tobias (2004), Uptake and collision dynamics of gas phase ozone at unsaturated organic interfaces, J. Phys. Chem. A, 108(27), 5806-5814, doi:10.1021/jp0494584.

Vlasenko, A., I. J. George, and J. P. D. Abbatt (2008), Formation of volatile organic compounds in the heterogeneous oxidation of condensed-phase organic films by gas-phase $\mathrm{OH}, J$. Phys. Chem. A, 112(7), 1552-1560, doi:10.1021/jp0772979

Wang, H. M., K. Hasegawa, and S. Kagaya (2000), The nitration of pyrene adsorbed on silica particles by nitrogen dioxide, Chemosphere, 41(9), 1479-1484, doi:10.1016/S0045-6535(99)00523-8.

Wang, H., S. F. Chen, L. Y. Li, and S. Y. Jiang (2005), Improved method for the preparation of carboxylic acid and amine terminated self-assembled monolayers of alkanethiolates, Langmuir, 21(7), 2633-2636, doi:10.1021/la046810w.

Wasserman, S. R., Y. T. Tao, and G. M. Whitesides (1989), Structure and reactivity of alkylsiloxane monolayers formed by reaction of alkyltrichlorosilanes on silicon substrates, Langmuir, 5(4), 1074-1087, doi:10.1021/la00088a035.

Williams, D. H., and J. Fleming (1989), Spectroscopic Methods in Organic Chemistry, McGraw-Hill, London.

Ziemann, P. J. (2007), Interactive comment on "Heterogeneous oxidation of saturated organic aerosols by hydroxyl radicals: Uptake kinetics and condensed-phase products" by I. J. George et al., Atmos. Chem. Phys. Discuss., 7(16), S3072-S3075.

A. K. Bertram and S. Gross, Department of Chemistry, University of British Columbia, 2036 Main Mall, Vancouver, BC V6T 1Z1, Canada. (bertram@chem.ubc.ca) 